\title{
A Phenomenological Study of Living with Excess Facial Hair for African-American Women
}

\author{
Courtney M. Pate
}

Follow this and additional works at: https://researchrepository.wvu.edu/etd

\section{Recommended Citation}

Pate, Courtney M., "A Phenomenological Study of Living with Excess Facial Hair for African-American Women" (2015). Graduate Theses, Dissertations, and Problem Reports. 6383.

https://researchrepository.wvu.edu/etd/6383

This Dissertation is protected by copyright and/or related rights. It has been brought to you by the The Research Repository @ WVU with permission from the rights-holder(s). You are free to use this Dissertation in any way that is permitted by the copyright and related rights legislation that applies to your use. For other uses you must obtain permission from the rights-holder(s) directly, unless additional rights are indicated by a Creative Commons license in the record and/ or on the work itself. This Dissertation has been accepted for inclusion in WVU Graduate Theses, Dissertations, and Problem Reports collection by an authorized administrator of The Research Repository @ WVU.

For more information, please contact researchrepository@mail.wvu.edu. 
A Phenomenological Study of Living with Excess Facial Hair for African-American Women

Courtney M. Pate MSN, FNP-c

Dissertation submitted

to the School of Nursing

at West Virginia University

in partial fulfillment of the requirements for the degree of

Doctor of Philosophy in

Nursing

\author{
Mary Jane Smith, $\mathrm{PhD}$, RN, Chair \\ Joy Buck, PhD, RN \\ Bernadine Lacey, PhD, RN, FAAN \\ Gina Maiocco, PhD, RN \\ Elizabeth Shelton, PHD, RN
}

Department of Nursing

\author{
Morgantown, West Virginia
}

2015

Keywords: excess facial hair, hirsutism, African-American women, health related quality of life, phenomenology, story theory

Copyright 2015 Courtney M. Pate MSN, FNP-c 


\begin{abstract}
A Phenomenological Study of Living with Excess Facial Hair for African-American Women
\end{abstract}

Courtney M. Pate MSN, FNP-c

Excess facial hair is a characteristic of hirsutism and can alter a woman's presentation of self in living day-to-day. Research is sparse in the realm of studying women who do not suffer from polycystic ovarian syndrome and have excess facial hair. Women of varying racial backgrounds are also underrepresented in the current literature. The purpose of this study was to describe the structure of meaning of living with excess facial hair for African-American women. The stories of eight women were gathered and analyzed using van Manen's phenomenological approach and middle range story theory. Five themes that resulted in the findings of the study were explicated. The structure of meaning of living with excess facial hair for African-American women is: (a) encountering a repugnant revelation detected by self and others; (b) exercising the obligation to tweeze, wax, thread, shave, or conceal in an attempt to control the uncontrollable; (c) discerning a self-imposed response to others' words and actions; (d) bringing to the forefront disapproving thoughts and feelings of being masculine, unattractive, and embarrassed; and (e) making up one's mind to accept that which cannot be changed. The findings are discussed in relation to three dimensions of health related quality of life as well as components of story theory. The theoretical and practical implications of the findings are also offered. 


\section{DEDICATION}

Dedicated to my loving husband, Dwayne Pate Jr., my son, Trey, and my daughter, Hunter, for without

their love and understanding this would not have been possible. 


\section{ACKNOWLEDGEMENTS}

I would like to acknowledge several people who assisted me along this journey. I would like to thank Dr. Mary Jane Smith for the guidance that you have provided throughout the dissertation process. Thank you for bringing out the abstract thinker in me. I can never thank you enough for those late night sessions of scholarly discourse. I am very grateful to my committee members, Dr. Gina Miaocco, Dr. Joy Buck, Dr. Elizabeth Shelton, and a special thank you to Dr. Bernadine Lacey. I thank you Dr. Lacey for introducing me to this academic endeavor and convincing me that five years was not going to be as long as I thought it was going to be.

I wish to acknowledge my friends for life Shavon Darden and Veronica Gallo. We started this journey together. We laughed and cried, welcomed life changes and challenges, and did everything that people said not to do while in a doctoral program. Thank you ladies for helping "failure is not an option" become a reality.

To my family and friends who are just as proud of me as I am in this moment I thank you. Thank you for giving me the opportunity to make you proud. Thank you for your prayers and pushes to help me to get to the end of the tunnel. You can all now say you know a doctor personally. 


\section{Table of Contents}

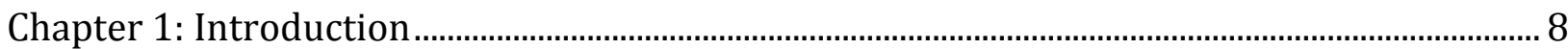

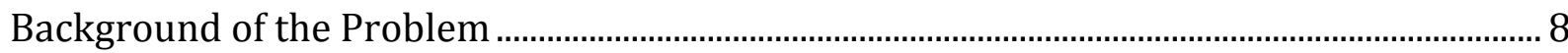

Problem statement ............................................................................................................................ 8

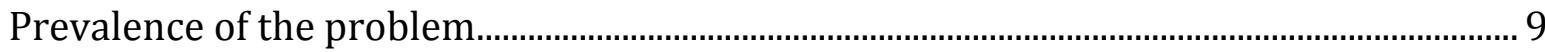

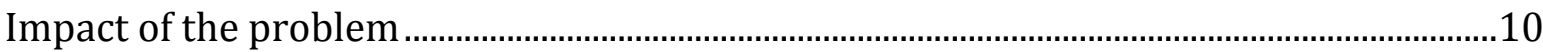

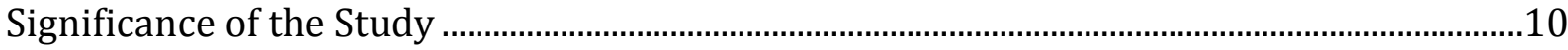

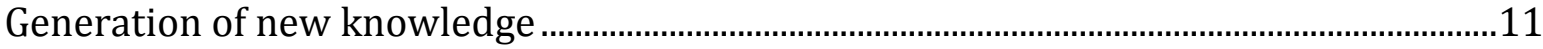

Generation of nursing knowledge ...........................................................................................11

Contribution to nursing practice ................................................................................................12

Major Constituents of the Study.................................................................................................12

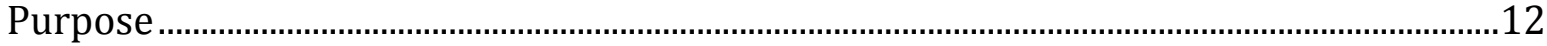

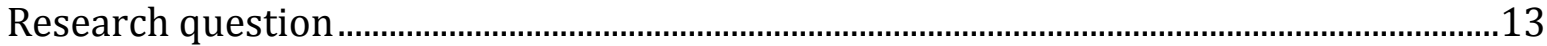

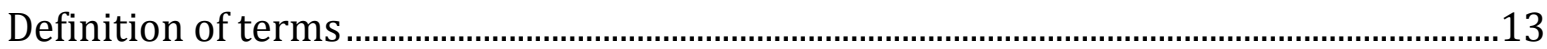

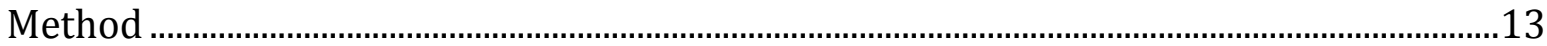

Theoretical rationale

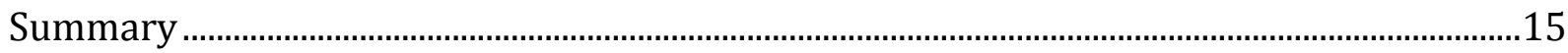

Chapter 2: Literature Review......................................................................................................16

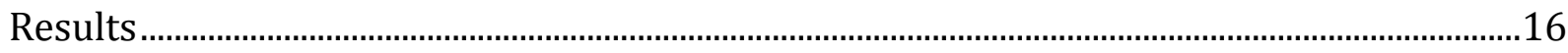

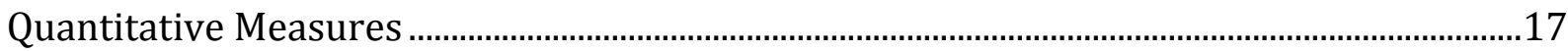

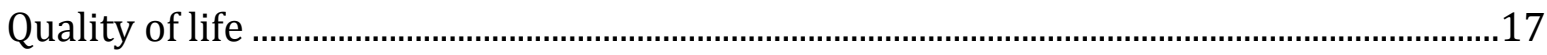

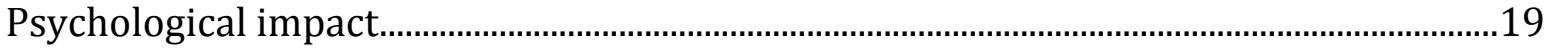

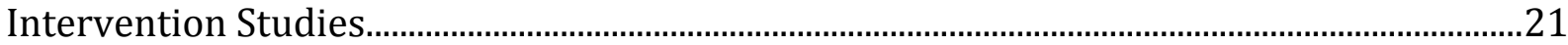

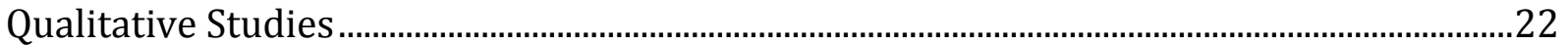

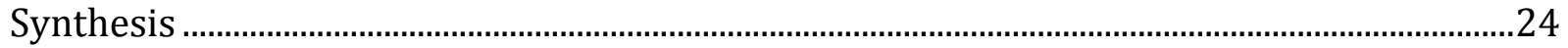

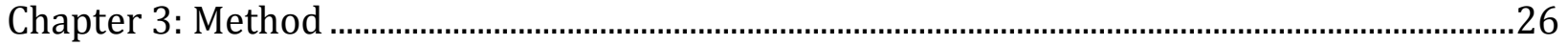

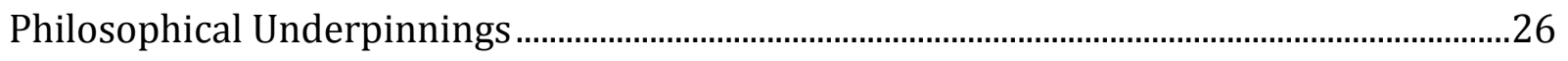

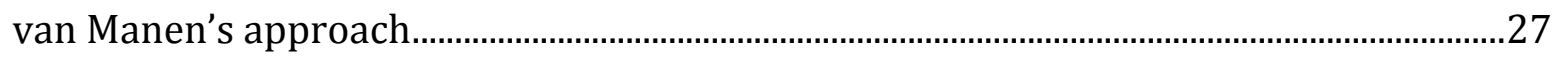

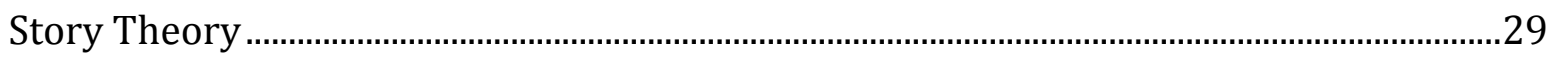

Human Rights Considerations (IRB) .....................................................................................

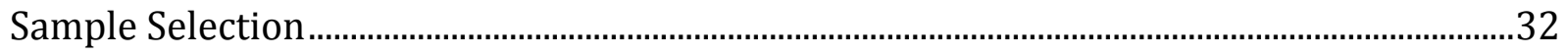




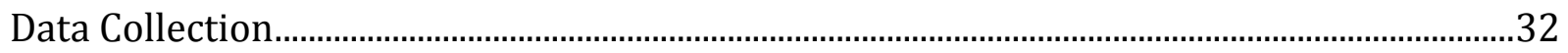

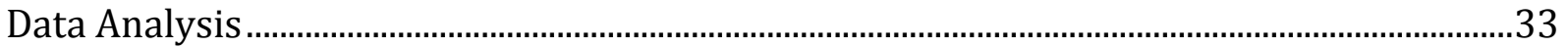

Methods to Assure Rigor ..................................................................................................................

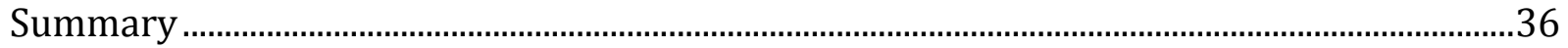

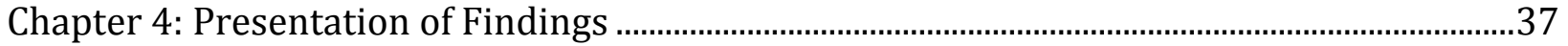

Description of participants ...................................................................................................

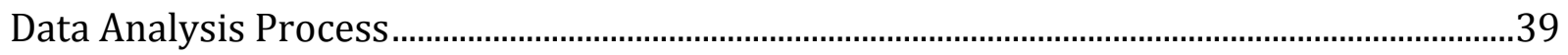

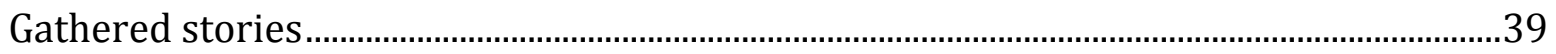

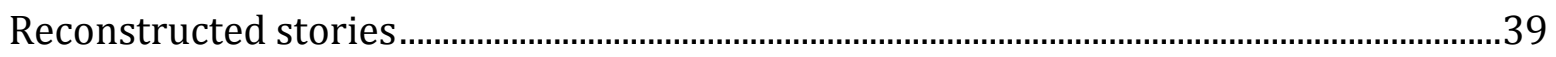

Validated reconstruction........................................................................................................

Identified essential statements in each story .......................................................................40

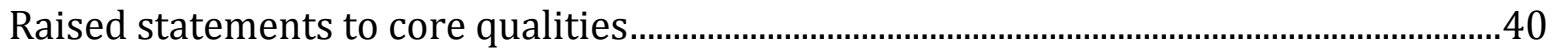

Synthesized qualities to reveal themes................................................................................. 41

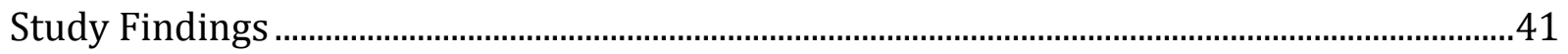

Encountering a repugnant revelation detected by self and others......................................42

Exercising the obligation to tweeze, wax, thread, shave, or conceal in an attempt to control the uncontrollable.....................................................................................................4

Discerning a self-imposed response to others' words and actions. ....................................4

Bringing to the forefront disapproving thoughts and feelings of being masculine, unattractive, and embarrassed....................................................................................................50

Making up one's mind to accept that which cannot be changed...........................................51

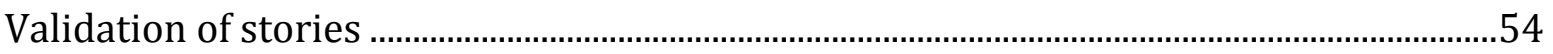

An African-American perspective …………………….........................................................56

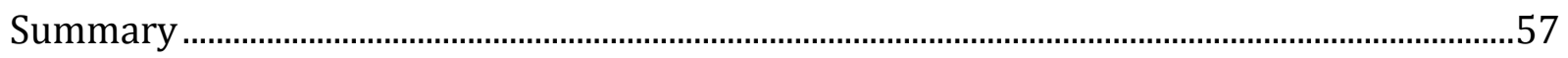

Chapter 5: Discussion ................................................................................................................

Health-Related Quality of Life.........................................................................................................59

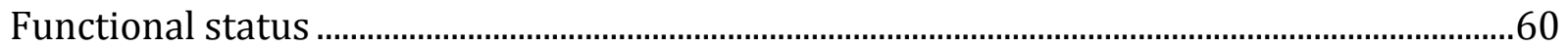

General health perceptions...........................................................................................................6

Overall quality of life.......................................................................................................................62

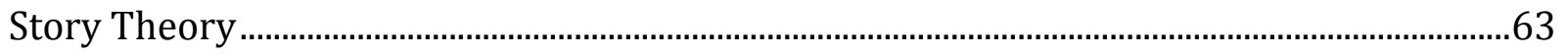

Significance of the Findings to the Knowledge Base of Nursing................................................65

Implications for Research......................................................................................................6

Implications for Practice ..........................................................................................................6 


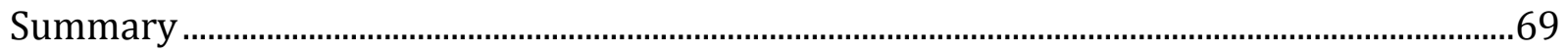

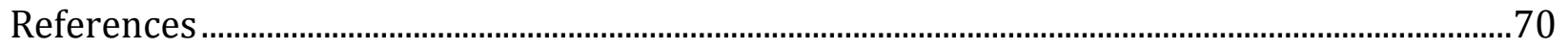




\section{Chapter 1: Introduction}

The purpose of this chapter is to introduce the background, significance and major constituents of this study. The problem will be stated, along with the prevalence and impact of the problem. The significance of this study to the discipline of nursing through the lens of generating new knowledge will be explicated. Practice implications that may stem from the study will also be offered. The chapter will conclude with presenting the purpose, research question, and method.

\section{Background of the Problem}

\section{Problem statement}

Excess facial hair can alter a woman's presentation of self in living day-to-day. Among African-Americans, self-presentation that conveys respect and care for oneself is more important than emphasis on ideal body weight (Rubin, Fitts, \& Becker, 2003). In studies where body aesthetics in women was explored, it was found that women who identify as African-American, place more emphasis on body ethics, style, and grooming, than the dominant Western culture. Body aesthetic is a belief that beauty is thin (Mossavar-Rahmani, Pelto, Ferris \& Allen, 1996; Rubin, Fitts, \& Becker, 2003). The Western cultural idealization of beauty as being thin has been linked to the prevalence of body dissatisfaction and eating disorders throughout history. African-Americans have greater appreciation of larger body shapes and less idolization of thinness (Miller \& Pumariega, 2001). Attractiveness as identified by African-American women is comprehensive and includes components of dress and overall appearance (Mossavar-Rahmani, Pelto, Ferris \& Allen, 1996). Various studies explored body dissatisfaction in terms of racially salient characteristics (i.e. skin color, hair texture, facial features), however the presence of 
excess facial hair was not included as a factor that may promote body dissatisfaction (Falconer $\&$ Neville, 2000 and Warren, 2012).

\section{Prevalence of the problem}

Excess facial hair is a characteristic of hirsutism. Hirsutism is the presence of coarse hairs in females in a male growth pattern (Azziz, Carmina, \& Sawaya, 2013). Often times this hair is noted on the face, back, or chest (Dawber, 2005). Hirsutism affects approximately 5\%-10\% of women of reproductive age across all ethnicities (Azziz, 2013). It was once estimated that approximately four million women in the United States were living with hirsutism (Azziz, 2003). The majority of women who present with hirsutism also have polycystic ovarian syndrome (PCOS), which causes elevated androgen levels (Azziz, Sanchez, Knochenhauer, Moran, Lazenby, Stephens, Taylor, \& Boots, 2004). However, up to $15 \%$ of all women have idiopathic hirsutism, which is diagnosed once all other causes have been excluded (Azziz, 2013).

Different tools are used to assess hirsutism. The Ferriman Gallwey Index is a subjective tool that can be utilized by clinicians to determine a diagnosis of hirsutism as well as the degree of facial hair, which includes mild, moderate, or severe (Ferriman \& Gallwey, 1961). The index uses a rating system of 0 (no excessive terminal hair growth) to 4 (extensive terminal hair growth) to measure the presence of male pattern hair growth in body areas to include, but not limited to the lip, chin, breast, back and buttocks (Ferriman \& Gallwey, 1961). A total score of eight has traditionally been used to make a diagnosis of hirsutism (Ferriman \& Gallwey, 1961).

Research is sparse in the realm of studying women who do not suffer from PCOS, who have excess facial hair. Women of varying racial backgrounds are also underrepresented in the current literature. The majority of women in the current literature have fair, white skin. Women with darker skin such as African-Americans are sparsely represented. To date, little to no 
research has been designed to explore the meaning of living with excess facial hair from the perspective of African-American women.

\section{Impact of the problem}

Women with excess facial hair spend time and money on improving their appearance through plucking, tweezing, waxing, laser hair removal, medication, and epilation. The time and energy spent on correcting this problem has been shown to have a negative effect on quality of life and mental health status (Snyder, 2006). With the established negative impact on quality of life and mental health status excess facial hair has been shown to be a potentially devastating issue related to the human health experience among those who are affected (Clayton, Lipton, Elford, Rustin, \& Sherr, 2005; Coffey \& Mason, 2003; Dixon, Hicks, \& Chapman, 1991; Keegan, Liao, \& Boyle, 2003; Lipton, Sherr, Elford, Rustin, \& Clayton, 2006; McCook, Reame \& Thatcher, 2005; Rabinowitz, Cohen, Le Roth, 1983; Zanganesh, Jafarabadi, Naghizadeh, Abdedinia, \& Haghollahi, 2012). Excess facial hair changes a woman's presentation of self in living the day-to-day.

\section{Significance of the Study}

The problem of excess facial hair for African-American women came from the researcher's practice. As an advanced practice nurse practitioner working in the field of laser hair removal the researcher came to understand the impact of excess facial hair on the lives of African-American women. The stories told by these women included the barriers that having excess facial hair placed on their lives related to decisions that other's close to them took for granted. The women also shared the reasons that they hesitated to have their hair reduced permanently, including the risk of burns from laser treatment. 
These women expressed the burden that having excess facial hair has on living an unencumbered life.

\section{Generation of new knowledge}

A description of the lived experience of African-American women with excess facial hair is absent from the literature. The absence of representation of this population in prior studies led to the research question, What is the structure of meaning of living with excess facial hair for African-American women? It is important to explore the experience of living with excess facial hair for those who are not represented in the literature including African-American women. Exploring this topic from the vantage point of the participant may give insight into how having excess facial hair impacts relationships, thoughts, feelings, and actions. Even though the appearance of facial hair may be more visible in groups of women of lighter complexions, the point of view in the study is that excess facial hair impacts all women despite skin tone.

\section{Generation of nursing knowledge}

Newman, Sime, and Cochran-Perry (1991) sum up the ontology of nursing with the following parsimonious definition "Nursing is the study of caring in the human health experience" (p.3). Smith (2014) postulates that "the growth of the discipline of nursing is dependent on the systematic and continuing application of nursing knowledge in practice and development of new knowledge" (p.11). Exploration of the research question is expected to generate an understanding of the human health experience of African-American women living with excess facial hair. Through this study the foundational groundwork necessary to further explicate the experience of living with excess facial hair for African-American women will be established. In capturing the lived experience of this ethnic group of women, themes related to 
their day-to-day life will be identified. The identification of these themes is expected to provide the basis for further development of clinical practice and research questions related to this topic.

Gaining this knowledge from the lived experiences of these women will provide a basis for including them in future research related to excess facial hair. Exploring this particular human health experience is expected to be a valuable asset to nurses caring for these women. Having an understanding of what these women go through may shed light on a topic that is often ignored or viewed as vain by society. This newly found understanding is expected to empower nurses to become empathetic to the struggles that these women face.

\section{Contribution to nursing practice}

As the scope of nursing practice continues to expand into various areas of the health care system, nurses are in a position that allows them hands on access to all women, including those who have excess facial hair. Advanced practice nurses, who practice in the primary care setting and in women's health, are also in the unique position of being able to offer care to women who have concerns about excess facial hair. The field of dermatologic nursing continues to grow, which affords nurses even greater access to these women. This access to women with facial hair growth allows nurses an opportunity to identify and address the condition, as well as implement change that may impact women by improving their quality of life and mental health status.

\section{Major Constituents of the Study}

\section{Purpose}

The purpose of this study is to explore the structure of meaning of living with excess facial hair for African-American women. Through the processes of reflection and dwelling with the lived experience, essential themes will be identified. These themes will create the structure of meaning. Understanding the experience of living with excess facial hair will enable nurses 
and other health care professionals to become better informed about a woman's experience of living with excess facial hair. Lastly, this qualitative study may stimulate future nursing research related to this problem among women.

\section{Research question}

This exploration will be guided by the question, What is the structure of meaning of living with excess facial hair for African-American women?

\section{Definition of terms}

Excess facial hair is the male pattern growth of coarse hair on women's upper lip, sideburn, chin, jaw line, and/or neck. The presence of excess facial hair will be determined by the participant's rating of facial hair as one or greater on a modified Ferriman-Gallwey scale (Harrison, Somani, \& Bergfeld, 2010).

\section{Method}

The intent of this study is to explore the structure of meaning for African-American women living with excess facial hair. Therefore, hermeneutic phenomenology, from the view of Max van Manen, which is rooted in philosophy and the human sciences, was chosen as the method for this study (1997). The middle range nursing theory, story theory, developed by Smith and Liehr, will serve as an additional framework for inquiry (2014).

\section{Theoretical rationale}

Phenomenology focuses on capturing the lived experience as a person experiences life (van Manen, 1997). Van Manen (1997) believes that the lived experience is the "breathing of meaning" (p. 37). Phenomenology is "the systematic attempt to uncover and describe the internal meaning structures of lived experience" (van Manen, 1997, p.10). According to van Manen (2014) the aim of phenomenology is to "collect examples of possible lived experiences in order 
to reflect on the meanings that may inhere in them" (p. 313). It is utilized to better understand the nature of meaning of everyday experiences by asking What is this experience like? (van Manen, 1997). Through a process of reflection the researcher uncovers a deeper understanding of the meaning generated from the participants' narratives (van Manen, 1997).

According to Smith and Liehr (2014), the human story is a health story that recounts one's current life situation to clarify present meaning in relation to the past with an eye toward the future. Story theory is congruent with Reed's (1999) ontological perspective that "story is an inner human resource for making meaning” (p. 205). Smith and Liehr (2014) further contend, "stories are a fundamental dimension of the human experience" (p. 225). The purpose of this theory is to " describe and explain story as the context for a nurse-person health promotion process" (Smith \& Leihr, 2014, p. 225). Story theory is based on "three interrelated concepts: (1) intentional dialogue, (2) connecting with self-in-relation, and (3) creating ease" (Smith \& Liehr, 2014, p. 229).

Story theory concepts will be applied throughout the study. Intentional dialogue is the "purposeful engagement with another to summon the story of a complicated health challenge" (Smith \& Liehr, 2014, p. 230). "A complicated health challenge is any circumstance where life change or pattern disruption generates uneasiness in everyday living” (Smith \& Liehr, 2014, p. 235). Excess facial hair will serve as the complicated health challenge in this study. Connecting to self-in-relation is "the active process of recognizing self as related with others in a story plot" (Smith \& Liehr, 2014, p. 231. Revealing personal history by focusing on the past, present, and future in relation to living with excess facial hair will create the developing story plot. Creating ease is "an energizing release experienced as the story comes together in movement toward resolving" (Smith \& Liehr, 2014, p. 232). Having the participant read her reconstructed story 
may create ease by illuminating an issue that is important. These fundamental principles will serve as a guide to the researcher throughout the process of gathering the story for the phenomenological inquiry.

Through the utility of phenomenology and story theory a rich description of the phenomenon under investigation is expected to be achieved. Story theory places the participant at the focal point of attention as the nurse researcher acts as an engaged guide. The researcher asking What is it like to live with excess facial hair? will set the course for story gathering. Smith and Liehr (2014) suggest that the story path begin with the present, prior to focusing on the past and then the future. With this in mind the participant will be prompted to relate to self in the present, past, and future, while connecting with self through personal history and selfreflection (Smith \& Liehr, 2014). As the story unfolds, clarifying questions related to what is being shared are asked related to the thoughts and feelings of the participant about living with excess facial hair.

\section{Summary}

Excess facial hair is a condition that affects women of many ethnic groups including African-American. Nurses are poised to interact with these women as well as influence how the women resolve this condition. To date, research related to excess facial hair with the goal of understanding the structure of meaning for African-American women living with excess facial hair is scarce. This qualitative study will lay the groundwork for providing a voice to a group of women that prior research has excluded. In order to gain first-hand insight into the experience of African-American women living with excess facial hair van Manen's (1997) phenomenological method and Smith and Liehr's (2014) story theory will guide the inquiry. 


\section{Chapter 2: Literature Review}

This chapter will describe research on excess facial hair through presentation of the literature. This literature review presents what is known about women living with excess facial hair. Methods used to generate this knowledge are also explored. The chapter concludes with a discussion of gaps in the literature and justification for research to explore the meaning of the experience of living with excess facial hair for African-American women.

Multiple databases were examined for literature related to facial hair. The databases included PubMed, CINAHL, Academic Search Complete, PsychInfo, and HealthSource for Nurses. Key words and phrases to locate relevant information included combinations of the terms hirsutism, unwanted facial hair, quality of life, depression, and anxiety. Hirsutism is the closest medically descriptive term for excess facial hair. Anxiety and depression were included as keywords due to the established findings that women with hirsutism may also have these mental disorders. Polycystic ovarian syndrome (PCOS) was not used as a search term due to the established findings that quality of life of women with PCOS is impacted by factors such as infertility and menstrual cycle irregularities, in addition to hirsutism. However, for the most part, hirsutism was studied in the literature as a symptom of PCOS.

\section{Results}

Numerous studies on hirsutism were identified ( $\mathrm{n}=185)$, however, only studies published in refereed journals, that focused on quality of life and psychosocial well-being were included in this literature review. Articles focusing on the diagnosis and management of hirsutism, for example, without indication of the impact of hirsutism on quality of life were excluded. Articles that included participants under the age of eighteen were also excluded. This parameter eliminated the utility of six relevant articles that included participants between 15-17 years of 
age. The author reviewed abstracts for psychosocial and quality of life indicators. These indicators included the terms quality of life, health related quality of life, anxiety, depression, and self-esteem. Twelve of the identified studies, that met the inclusion criteria focused on the quality of life and psychosocial well-being of women with hirsutism. A narrow range of study aims and ethnicity of subjects was found. The majority of studies had a large percentage of Caucasian participants with ages ranging from 18-62. Sample sizes of the studies ranged from 10-128 participants.

\section{Quantitative Measures}

A variety of instruments were used to assess quality of life, depression, anxiety, and selfesteem of women with excess facial hair. The instruments most frequently used to measure quality of life were The Dermatology Life Quality Index (DLQI) and World Health Organization Quality of Life Assessment (WHOQOL-BREF). One study used the Health Related Quality of Life Questionnaire (PCOSQ) for women with Polycystic Ovarian Syndrome. The Rosenberg Self-Esteem Scale (RSES) was used to measure the self-esteem of women with hirsutism (Basra, Fenech, Gatt, Salek \& Finlay, 2008; World Health Organization, 1996; Cronin, Guyatt, Griffith, Wong, Azziz, Futterweit, et al., 1998; McCook, Reame, Thatcher, 2004; Zigmond and Snaith, 1983).

\section{Quality of life}

The WHOQOL-BREF is an abbreviated form of the WHOQOL-100. This instrument is made up of 26 items. Two items measure overall quality of health. The remaining 24 items measure the broad domains: psychological health, physical health, social relationships, and environment. Items are scored 1 (not at all) to 5 (completely) and a higher score is indicative of a higher quality of life (World Health Organization, 1996). Lipton et al., (2006) used the 
WHOQOL-BREF in addition to a questionnaire that evaluated hair removal practices, impact of facial hair on women's lives, and other measures of psychological morbidity to assess the psychological and behavior burden of women with facial hair. It was concluded from this study that women with excess facial hair have good quality of life scores overall, however their low scores in the psychological and social domains reflect the impact of the time and emotional burden having excess facial hair places on their lives. It also appeared that many women felt ashamed of their appearance and lacked self-confidence. Of the eighty-eight participants in this study $80 \%$ were Caucasian, $18 \%$ Asian, and the last 2\% were described as Mixed Race (Lipton et al., 2006).

Wong and Rivers (2009) concluded similar findings in their study. The relatively small sample included eighteen women with Fitzpatrick scores I-V. The ethnicities of these women were not revealed in the study. Questions related to level of embarrassment, self-consciousness, time spent taking care of hair, and interferences of treatment of unwanted hair on a daily schedule had the highest scores indicating the most impairment on quality of life as measured by the Dermatology Life Quality Index (DLQI) (Wong \& Rivers, 2009). Utilizing the DLQI in a population of Iranian women, Rahnama, Sohbati, and Safizadeh (2013), found that the symptoms and feelings portions of quality of life were where most participants were affected. The DLQI is a self-administered questionnaire made up of 10 questions that assess a patient's perception of the impact of a dermatologic condition on their quality of life over the last week. Aspects of life that are assessed include leisure, school or work, symptoms and feelings, daily activities, and side effects of treatment. A four-point Likert scale is used to assess each item. Individual items are scored from 0 (not at all) to 3 (very much) and added together to yield a total score of 0-30. 
Higher scores are indicative of greater impairment to one's quality of life (Basra, Fenech, Gatt, Salek \& Finlay, 2008).

The PCOSQ is a 26-item questionnaire that includes five domains: emotions, body hair, weight, infertility, and menstrual problems. Each item is rated on a 7-point scale, 1(a severe problem) to 7 (no problem). Lower scores indicate a greater adverse impact of PCOS on the woman's quality of life (Cronin, Guyatt, Griffith, Wong, Azziz, Futterweit, et al., 1998; Guyatt, Weaver, Cronin, Dooley \& Azziz, 2004). In a cross-sectional, correlational study, it was found that in relation to PCOS hirsutism was the symptom with the least amount of concern compared to obesity and infertility (McCook, Reame, and Thatcher, 2005). However, women with hirsutism reported feeling moody, worried, depressed, and having low self-esteem (McCook, Reame, \& Thatcher, 2005). In this study the PCOSQ was the measure of quality of life, and of the 128 women 97\% were Caucasian (McCook, Reame, \& Thatcher, 2005).

\section{Psychological impact}

Most identified studies utilized the Hospital Anxiety and Depression Scale (HADS) to assess anxiety and depression. The HADS was developed for patients in non-psychiatric acute care hospitals. This instrument is made up of 14 items and 2 subscales, anxiety and depression, and each of the items are scored on a 4-point scale of 0 (not at all) to 3 (definitely). This instrument is helpful in identifying possible and probable anxiety and depression among subjects (Zigmond \& Snaith, 1983).

A review of articles related to hirsutism, anxiety, and depression revealed that women with hirsute appearances had higher HADS scores for both anxiety and depression than women newly diagnosed with gynecological cancer and other cancer patients (Keegan, et al., 2003; Lipton, et al., 2006). In these studies the severity and causes of hirsutism were not reported. 
Women with hirsutism also reached clinically significant levels for anxiety and depression, however more often for anxiety than for depression. In these studies the samples consisted of 79.2\% and 80\% Caucasian women, respectively (Keegan, et al., 2003; Lipton, et al., 2006). The findings in this study are supported by Zanganesh, Jafarabadi, Naghizadeh, Abdedinia, and Haghollahi, (2012), who found that women with hirsutism were 3.1 times more likely than others to have high levels of anxiety $(n=81)$, according to responses on the Understanding Yourself questionnaire. Studies consistently show that psychological distress is associated with the severity of the women's perceived facial hair (Keegan, et al., 2003; Lipton, et al., 2006). This finding suggests that women with even small amounts of facial hair may have some degree of psychological impairment.

The Rosenberg Self-Esteem Scale (RSES) was utilized in several hirsutism related studies. The RSES is a 10-item inventory that utilizes a 4-point Likert scale, 1(strongly agree) to 4 (strongly disagree). When positively worded items are reverse scored a low score indicates low self-esteem. Scores range from 10-40 (Rosenberg, 1989). Women with hirsutism were not found to have lower levels of self-esteem when compared to the general public (Keegan, et al., 2003; Lipton, et al., 2006).

Through utilizing the various psychological instruments of measurement researchers have significantly substantiated the claim that hirsutism impacts the psychological well-being of affected women. Women with hirsutism appear to have greater self-reported levels of anxiety and depression than women of the general public and those with diseases such as cancer. Quality of life of women with hirsutism is compounded by several factors including the time spent attending to their hair as well as the presence of other issues such as infertility and obesity. 


\section{Intervention Studies}

A number of studies investigate laser hair removal as an intervention to improve quality of life in hirsute women. In all intervention studies laser hair removal was shown to improve quality of life among participants as measured by either the DLQI or WHOQOL-BREF (Clayton, et al., 2005; Conroy, Venus, \& Monk, 2006; Maziar, Farsi, Mandegarfard, Babakoohi, Gorouhi, Dowlatt, \& Firooz, 2010; Wong \& Rivers, 2009). The scores on the DLQI improved by a decrease of up to 6 points from pre to post treatment (Wong \& River, 2009; Maziar, 2010; Conroy, et al., 2006). This increase in score may be attributed to women no longer having to spend extended time removing facial hair through time-consuming measures such as plucking and shaving, as well as their improved physical appearance.

In a longitudinal study, participants were asked to complete the DLQI before their first, fourth, and sixth laser and or light hair removal treatments $(n=18)$. All of the participants in the study were a I-V on the Fitzpatrick scale. As expected, DLQI scores did not significantly improve between treatments one and three, due to little apparent physical change at that point in time. However there was a statistically significant difference in scores between the second and third as well as first and third questionnaire scores $(\mathrm{p}<.05)$. The researchers attribute this improvement in quality of life scores to the finding that the most pronounced change in physical appearance takes place between the third and sixth laser treatment (Wong and Rivers, 2009).

In a randomized control trial of five high-fluence laser treatments, researchers found that compared to the control group $(n=37)$ the intervention group $(n=51)$ had a significant improvement in psychological quality of life as well as a significantly greater decrease in anxiety and depression scores (Clayton, et al., 2005). The sample in this study was described as predominately Caucasian. Self-reported severity of facial hair decreased from 7.3 to 3.6 for the 
intervention group and 7.1 to 6.1 in the control group. The change was statistically significant in the intervention group (Ancova $\mathrm{F}(1,83)=2.5, \mathrm{p}<.05)$. The intervention group spent less time a week removing facial hair from 112 to 21 minutes/week compared to the control groups 92 to 56 minutes/week (Clayton, et al., 2005).

These studies suggest that laser hair removal interventions have the potential to improve the quality of life of women affected by hirsutism. Women in these studies experienced improvements in levels of anxiety and depression. Post-intervention they were also able to spend less time focused on hair removal. Women with Fitzpatrick skin types ranging from a medium V to VI were excluded in intervention studies due to their unsuitability to be treated with the Alexandrite lasers used in the studies. This includes women who have skin that is sun insensitive, always tans, uncommonly or never burns, and highly pigmented dark skin (Fitzpatrick, 1988). Women with these skin characteristics tend to be of varying ethnicities.

\section{Qualitative Studies}

Qualitative research related to hirsutism is heavily influenced by PCOS studies. In contrast to findings of quantitative studies, which rank excessive hair growth as least concerning, excessive hair growth in women with PCOS has been found to be the second most serious related symptom that negatively impacts quality of life when studied qualitatively (Guyatt, Weaver, Cronin, Dooley, \& Azziz, 2004). Two of the four qualitative studies identified focused primarily on the experience of women with hirsutism. The primary focus of the other three studies was the experience of women with polycystic ovarian syndrome.

Through qualitative content analysis of the experience of Swedish and Mediterranean women living with hirsutism it was found that these women experienced their body as yoke, a freak, a disgrace, and a prison $(n=10)$ (Ekback, Wijma, Benzein, 2007). These descriptions were 
similar to the findings of Kitzinger and Willmott, in which women felt freakish, abnormal, and not proper women $(n=30)$ (2002). Of the thirty women in this study twenty-four of them were Caucasian. The identified descriptions of self, identified by these women, are not solely related to the appearance of hirsutism. The participants were also impacted by irregular, absent, or disrupted menstrual cycles and infertility symptoms in addition to excessive hair growth (Kitzinger and Willmott, 2002).

Keegan et al. (2003) used semi-structured interviews during the second phase of their study in order to seek information not easily obtained by quantitative survey methods $(n=4)$. Keegan et al. (2003) the following questions:

How the women came to construe their hair growth as problematic;

What are perceived acceptable levels of facial and body hair for women; and What are the collective ideas about female hair growth that construct women's experience of unwanted hair growth? (p. 336)

The researchers chose to use a discourse analytic approach to guide their analysis of the information obtained during the interview. Themes identified during the analysis phase were that: hair was an abnormal norm; hair as sexing men and women; and unwanted hair as dirt, deviance, and stigma (Keegan et al., 2003). The women expressed having excessive hair makes them feel dirty and does not fit the cultural norm of women being smoothed-skinned and hairless. Furthermore the women expressed that having hair in certain areas such as on the face demarcates masculinity and femininity. As in previous studies these women also identified themselves as "freaks", but also added that this self-placed stigma has led them to adapt methods of "passing" including the use of depilatory products and medical treatments (Keegan et al., 2003). 
In a phenomenological study women acknowledged how hirsutism impacts femininity. Women reported that having hair present on their breast as well as their face caused them to feel less feminine (Snyder, 2006). All women in this study, ten of which were Caucasian and two African-American $(n=12)$, invested not only time, but also money in removing their unwanted hair. Methods of hair removal included plucking, waxing, shaving, using electrolysis, laser therapy, over the counter creams, and prescription medications (Synder, 2006). Women in the study expressed that they wanted to feel normal, which included having a less hirsute appearance. However, these women were frustrated with methods of hair removal that are thought to be permanent, such as electrolysis and laser treatments, not being covered by health insurance (Snyder, 2006).

In a pilot study by Pate (2013), where story-gathering and analysis were utilized, high points, low points, and turning points in one African-American woman's experience of living with facial hair were identified. The participant in this study did not have a diagnosis of PCOS. The lack of a diagnosis led the participant to express feelings of experiencing a puzzling health challenge that impacted her psychological well-being, which was characterized as a low point (Pate, 2013). Having access to hair removal devices such as shaving and plucking served as a high point, while finding a more permanent method, laser hair removal, served as a turning point for the participant (Pate, 2013).

\section{Synthesis}

The literature related to the lived experience of women with excess facial hair is parsimonious. The quantitative literature focused on the impact of treatment on the lives of women with excess facial hair, as well as the overall quality of life and psychological impact related to excess facial hair (Clayton, et al., 2005; Keegan, et al., 2003; Lipton, et al., 2006; 
Wong and Rivers, 2009; Rahnama, Sohbati, \& Safizadeh, 2013). The qualitative studies provide evidence that hirsutism as a symptom of PCOS has an impact on the way women feel about themselves (Snyder, 2006). Furthermore women with hirsute appearance feel less feminine then their "normal" counterparts (Kitzinger \& Wilmott, 2002). Although excess facial hair is not the only symptom of PCOS that impacts a woman's quality of life, it is a symptom that carries a financial burden and has a psychological impact (Snyder, 2006).

Of all of the identified studies only two indicate that African-Americans were included in their sample (Snyder, 2006; Pate, 2013). It is concluded that the stories of African-American women with excess facial hair are not adequately presented in the literature. There is an overall gap in the literature regarding what it is like for a woman to live with excess facial hair. Findings from the literature review support the need for qualitative work that addresses the question, What is the structure of meaning of living with excess facial hair in African-American women? This study was designed to address this gap by exploring the meaning of having excess facial hair from the perspective of African-American women. 


\section{Chapter 3: Method}

The research question addressed in the study was, What is the structure of meaning of living with excess facial hair for African-American women? A review of the literature related to excess facial hair indicated that a gap existed in regard to understanding what it is like for African-American women to live with excess facial hair. Qualitative research methods are utilized when information related to phenomena tends to be sparse, as such in the case of African-American women with excess facial hair. The main epistemological basis for qualitative research is human experience, however lived experience "possesses special methodological significance" (van Manen, 2014, p. 39).

This chapter presents the philosophical underpinnings, which serve as a guide for this research. Discussion of the underpinnings includes the philosophy of phenomenology, van Manen's approach to hermeneutic phenomenology, and a description of story theory, a middle range nursing theory. The remainder of the chapter includes the procedural steps of the methodology, description of participant recruitment, discussion of data collection and analysis, maintenance of rigor, and protection of human subjects throughout the study.

\section{Philosophical Underpinnings}

Phenomenology is not just a philosophic method for questioning, but also a philosophical perspective (van Manen, 2014). Edward Husserl, who is considered the intellectual founder of phenomenology, defines phenomenology as a "descriptive philosophy of the essences of pure experiences" (van Manen, 2014, p. 89). Phenomenology brings to the forefront the tenets upon which all human understanding is grounded and investigates the way that knowledge comes into existence (van Manen, 2013). One essential principal to the foundation of phenomenology is the notion of intentionality. Intentionality is a term that Husserl adopted from his teacher Bretano. It 
describes the ways we are attached to the world, and how all our thinking, feeling, and acting is connected to things of the world. In essence even our consciousness is being conscious of something (van Manen, 2014). Husserl proposes that the most important part of phenomenology is the analysis of consciousness because this reveals how consciousness constitutes the objectivities (van Manen, 2014). Husserl further posits that things we are conscious of are not like objects in a box that can be removed and replaced, but are first revealed as what they are for us and what value they hold to us as a process of object intention (Husserl, 1970). In order for the world, or things of the world to be described, they must first be attached to a defining person's consciousness (van Manen, 2014). Lived experience is recollected process and requires one to reflect on moments that have passed (van Manen, 2014).

The development of hermeneutic phenomenology evolved with the emergence of Heidegger a student of Husserl. Heidegger focused on the original significance of being and not the meaning of being (van Manen, 2014). He believed that we are already submerged in meaning and that phenomenological perceptiveness is made possible through concealing and unconcealing meaning (van Manen, 2014). Hermeneutic phenomenology studies "how people interpret their lives and make meaning of what they experience" (Cohen et al., 2000b, p.5). It is a method that aims to abstain from dogmatizing. Through language and sensitive interpretation there is a focus on the prereflective aspects of living (van Manen, 2014).

\section{van Manen's approach}

Phenomenology was chosen to guide this study because it focuses on capturing the lived experience (van Manen, 1997). van Manen (1997) believes that the lived experience is the "breathing of meaning" (p. 37). Phenomenology is "the systematic attempt to uncover and describe the internal meaning structures of lived experience" (van Manen, 1997, p.10). The aim 
of phenomenology is to "construct an animating, evocative description of human actions, behaviors, intentions, and experiences as we meet them in the lifeworld" (van Manen, 1997, p. 19). Furthermore, it aims to "express, in rigorous and rich language phenomena as they give themselves, and it aims to investigate the conditions of origin and self-givenness of these phenomena" (van Manen, 2014, p. 61). Self-givenness refers to how a person comes to know and describe what is meaningful to him/her regarding the situation. Phenomenology not only focuses on developing meaning of a particular life experience it also explores one's knowing that a conscious experience has taken place. It is used to better understand the nature of meaning of everyday experiences by asking, What is this experience like? (van Manen, 1997). Through a process of reflection the researcher uncovers a deeper understanding of the meaning in the participant's narrative (van Manen, 1997). A hermeneutic path of six interrelated activities will guide the gathering and analysis of stories in this study: (1) turning to a phenomenon which is of serious interest; (2) investigating experience as lived rather than conceptualized; (3) reflecting on essential themes that characterize the phenomenon; (4) describing the phenomenon through the art of writing and rewriting; (5) maintaining a strong and oriented nursing relation to the phenomenon; and (6) balancing the research context by considering parts and the whole (van Manen, 1997).

van Manen (1997) stated that the inquiry of a phenomenon of serious interest begins with someone setting out to make sense of a certain aspect of human existence. He does not place any limitations or qualifications on the phenomenon of interest. The identification of this interest then leads to the formulation of a question. For example, interest in this phenomenon developed through the investigator's clinical experiences of caring for women with excess facial hair and 
wondering, What is it like to live with excess facial hair? The question, What is the structure of meaning for African-American women living with excess facial hair? is the result of that interest.

The second, third, and fourth activities described by van Manen (1997) build upon one another. Through a process of "turning "to the things themselves"” one engages in the reawakening of a phenomenon as it was lived (van Manen, 1997, p.32). In doing this, the essences of the experience are captured. Once the essences have been captured an active reflection commences, in which the obscure is brought into nearness (van Manen, 1997). The fourth activity, which is centered on the art of writing and rewriting, allows what shows itself to be seen as it has been shown in itself. This is achieved through language and thoughtfulness. A voice of the experience is developed and in turn heard through this explicative process (van Manen, 1997).

The fifth activity, which describes remaining attentive to the original question, guides the investigator throughout the entire phenomenological inquiry process. Being actively engaged prevents the investigator from wandering away from the question at hand, making wishy-washy innuendos, and reflecting on indulgent preoccupations (van Manen, 1997). The sixth activity, entails the examination of the parts of the developed writings as well as the whole of the writings for significance (van Manen, 1997). Although these activities have been presented in a numerical order it is important to recall that they are not to be performed procedurally, however van Manen (1997) posits that there is interplay amongst the activities.

\section{Story Theory}

According to Smith and Liehr (2014), the human story is a health story that recounts one's current life situation to clarify present meaning in relation to the past with an eye toward the future. Smith and Liehr (2008) further contend, "stories are the substance of qualitative 
research" (p. 219). Story theory is based on "three interrelated concepts: (1) intentional dialogue, (2) connecting with self-in-relation, and (3) creating ease" (Smith \& Liehr, 2003, p. 209). These fundamental principles will serve as a guide to the researcher throughout the process of gathering the story in the phenomenological inquiry.

The first concept, intentional dialogue, is the "purposeful engagement with another to summon the story of a complicated health challenge" (Smith \& Liehr, 2014, p. 230). Excess facial hair will serve as the complicated health challenge in this study. According to Smith \& Liehr (2014), a health challenge may be a naturally occurring development that creates uneasiness. Through the action of purposeful engagement the investigator will seek to connect with the participant to reveal her unique life experience. The second concept, connection with self-in-relation, is "the active process of recognizing self as related with others in a story plot" (Smith \& Liehr, 2014, p. 231). This concept will guide the investigator while actively and attentively guiding the participant. Connecting to self-in-relation asks the participant to "reflect on where they have come from, where they are now, and where they are going in life" (Smith \& Liehr, 2014, p. 231). Connecting to self-in-relation is built on the concept of reflective awareness that enables one to express thoughts, feelings, and actions, which lends itself to the revelation of deeper meaning related to having excess facial hair. The third concept, creating ease, is "an energizing release experienced as the story comes together in movement toward resolving" (Smith \& Liehr, 2014, p. 232). As the participant's story unfolds disjointed fragments are woven together in the nurse's presence to create a whole narrative made up of juxtaposed realities (Smith \& Liehr, 2014). These fundamental principles will serve as a guide to the researcher throughout the process of gathering the story for the phenomenological inquiry. 
The investigator shares Smith and Liehr's belief that "stories are the substance of qualitative research" (2014, p. 240). Subsequently, the investigator, as a nurse researcher, gathered the stories of African-American women with excess facial hair to reveal the ontological understanding of what it is like to live with excess facial hair. Through this activity, understanding for both the participant and the researcher was actualized.

\section{Human Rights Considerations (IRB)}

After approval by the dissertation committee, the researcher submitted the study proposal to the West Virginia University Institutional Review Board (IRB) for Protection of Human Subjects for consideration as a minimal risk study. Participants who met the inclusion criteria for the study and volunteered to participate were given a consent form that described the purpose and the procedures of the study. This consent form also informed participants of their right to refuse to participate in all or any part of the study, of methods used to protect privacy, such as separating identifying information from data, and a statement that any publications or public presentations of findings will be absent of identifying information. All participants were required to sign the consent form prior to the initial interview. Due to the realization that this study may have induced some psychological distress, the researcher also provided telephone numbers of local mental health professionals in the event any participant experienced psychological distress at any stage of the research process. The demographic data and transcribed interviews remained in a locked, secure location, in the researcher's office throughout the study and will remain secured for three years after analysis after which time the data will be shredded. 


\section{Sample Selection}

Sample selection was structured by the following inclusion criteria: women with an African American ethnic background, age greater than 18 years, English speaking, a score one on or greater the modified Ferriman-Gallwey scale, and no diagnosis of polycystic ovarian syndrome. The scale was modified to include only facial areas. The Ferriman-Gallwey scores were used to ascertain the level of facial hair perceived by the women.

Recruitment of participants involved many steps. Initially fliers were placed in beauty salons and churches asking African-American women with excess facial hair to consider sharing their story on how this condition impacted their lives. If the participant was interested, the woman contacted the researcher via telephone. During this telephone call the purpose of the research study was explained. A time and meeting location was also established during this call.

\section{Data Collection}

After being contacted by participants, the researcher met face-to-face with the women to conduct interviews at the location of their choosing. Three of the women chose to meet the researcher at the church where they saw the flier, while the other five women requested that the researcher meet them at their home. Before the interviews began, the researcher again explained study procedures and answered questions. Each participant then signed the IRB approved consent form. Once informed consent was obtained, the participants completed the FerrimanGallwey tool to establish eligibility to participate.

The story gathering began with the researcher stating, "Tell me what it is like to presently live with excess facial hair." Smith and Liehr (2014) suggest that the story path begin with the present, prior to focusing on the past then future. With this in mind the participant was prompted to relate to self in the present, then past, and finally future, while connecting with self 
through personal history and self-reflection (Smith \& Liehr, 2014). Throughout the story gathering a story line was used to direct discussions and, when warranted, the researcher redirected the participant back to the original question. The researcher also asked clarifying questions as well as prompted the participant to continue speaking, in order to achieve the goal of having the initial question answered. The interviews ranged from 30 minutes to one hour in length.

After each session, the researcher immediately reviewed the recorded interview and field notes. A journal of thoughts and feelings noting what prompted a line of questioning throughout the interviews was maintained. The researcher transcribed the recorded stories within twentyfour hours of the interview. After transcription, the researcher listened to the recordings again while reading the transcription to verify the participants' data was transcribed appropriately before moving to data analysis. After the eighth story was gathered, redundancy was apparent.

A second data collection period occurred as the researcher shared the reconstructed story with participants. This second data collection occurred for two reasons. First, this second encounter established credibility of findings as additional feedback was received concerning their story. Second, after completing initial interviews and reconstructing the participants' stories, the researcher realized that the initial comments of the participants lacked clarification of the impact or influence that being African American had on her situation. The researcher asked participants at this second meeting, "Tell me how having excess facial hair impacts you specifically as an African-American woman?

\section{Data Analysis}

According to van Manen analyzing themes and gathering stories is an interrelated process (1997). After gathering the stories, transcribed interviews were read and reread to 
uncover the structure of the story. Data analysis then occurred in this order. First, stories were reconstructed for each participant using the participant's words. The reconstructed story is composed of a beginning, middle, and end (Smith \& Liehr, 2014). The second level of analysis was to examine each sentence in the story by applying the question What does this reveal about the experience? (van Manen, 1997). During this second phase, essential descriptive statements were identified through selective reading. The third phase of analysis involved a process of identifying core qualities in the participants' stories. A core quality is an idea gleaned from the descriptive expressions from all of the participant stories. All of the essential descriptive statements were then listed under the core qualities thus moving analysis to encompass all of the reconstructed stories and setting the stage for theme analysis. During this part of the fourth phase of analysis, which is interpretive synthesis, the core qualities were lifted in abstraction to the interpretation of themes. A theme is the focal point of meaning captured by the researcher through interpretation (van Manen, 1997). The structure of meaning is a synthesis of the themes describing the lived experience (van Manen, 1997).

\section{Methods to Assure Rigor}

In this study, rigor was maintained by the researcher bracketing and by affirming credibility, confirmabilty, and dependability throughout the research process. Prior to collecting data the researcher took time to bracket her thoughts and feelings related to the question. Van Manen states that making explicit one's own understandings, beliefs, assumptions, presuppositions, and theories, through a process of bracketing, is necessary so that one does not interpret the nature of the phenomenon before asking the question (1990).

Credibility, the internal validity of findings, was met by taking steps to ensure that the study answered the question that it was intending to answer. Phenomenology and story theory 
are both well-established qualitative research methodologies. The adoption of well-established research methods is critical in establishing credibility (Shenton, 2004). By employing these research methods in all phases of the study the researcher was able to promote the trustworthiness of the study's findings. The participants were made aware that they had the right to withdraw from the study at any time. The researcher encouraged the participants to be open during discourse and used iterative questioning when appropriate to elicit clarification of information that was shared (Shenton, 2004). As another approach to ensure credibility, the participants in the study were asked to validate their descriptions of the phenomena of interest (Shenton, 2014). The development of rich descriptions is helpful in the sense that it exposes the context surrounding the phenomena as well as the phenomena itself (Shenton, 2014). By having the participants validate their stories the researcher affirmed that the findings were indeed congruent with the participant's reality.

Confirmability is the process to ensure that the findings were formulated from the data and not the researcher's preference. This was achieved by doing the following (Shenton, 2004). An audit trail was developed detailing step by step any research decisions made and procedures changed. During the interview process the researcher utilized an audit trail to guide the abovementioned iterative questioning. During the analysis process the researcher maintained an audit trail, which revealed how the data gave rise to themes identified in the findings. The aforementioned bracketing that the researcher engaged in prior to the study also served as a tenet of affirming confirmability.

Dependability, was met by in-depth reporting of research design and implementation, operational detail of data gathering, and reflective approval of the project (Shenton, 2004). For instance, the researcher included every step that was taken throughout the research process from 
data gathering to data analysis in this research report. Based on the descriptions provided, in this chapter, one could repeat this work, despite the likelihood that they may find similar, yet different results.

\section{Summary}

This chapter summarized study methodology. Using hermeneutic phenomenology and the nursing middle range story theory as philosophical underpinnings, the question explored was What is the structure of meaning of living with excess facial hair for African-American women? Sample selection, data collection procedures and analysis were outlined. van Manen's (1997) methodology of inquiry was followed during the data collection and analysis phases of the study. The investigator ensured that each participant's rights were protected throughout the study while conforming to the accepted standards of rigor for qualitative research and following IRB requirements. 


\section{Chapter 4: Presentation of Findings}

The purpose of this study was to determine the structure of meaning for African American women living with excess facial hair. Eight women were recruited and interviewed twice. The transcripts of the audio recordings were utilized to develop the reconstructed story for each participant. Essential statements identified in each story were used to develop the core qualities that were then integrated into themes to comprise the structure of meaning of living with excess facial hair from the perspective of African American women.

This chapter presents the description of the participants as well as a comprehensive description of the data analysis process and findings of the study. The analysis process incorporates four of van Manen's (1997) six activities that guide the collection and analysis of data as well as Smith and Liehr's (2014) story theory. The structure of meaning of living with excess facial hair for African American women is presented along with rich descriptions that support the themes in the structure of meaning. In addition validation of the reconstructed story by the participants and the African American women's thoughts on living with excess facial hair will be presented.

\section{Description of participants}

Each participant was assigned a pseudonym to be used in this study: Tanya, Nikki, Lisa, Tina, Debra, Ann, Kim, and Kiesha. Demographic data were hand-tabulated following the completion of the interviews. The ages of the participants ranged between 22-67, with at least one participant representing each generation. Three participants identified that they had facial hair for at least eight years. Another three participants stated that they had facial hair for at least ten years, while the remaining two participants stated that they had facial hair for over twenty years. 
The Ferriman-Gallwey scores obtained ranged from 2-16. Tanya is a 56 year-old, who has had facial hair for 25 years, had a total score of two. This self-rated score represents that she has sparse terminal hairs on her chin and lower jaw and neck. Nikki, a 50 year-old, who has had facial hair for 20 years, had a total score of fifteen. This self-rated score is indicative of: a moustache covering most of the upper lip and crossing the midline; thick growth over the sideburn area; entire chin covered with heavy growth; and light growth covering the lower jaw and neck. Lisa, a 54 year-old, who has had facial hair for 8 years, had a total Ferriman-Gallwey score of five, which indicates sparse hairs on the lip, sideburns, lower jaw and upper neck, as well as small-thickened areas on the chin. Tina, a 37 year-old, who has had facial hair for eight years scored two, which represents sparse terminal hairs with small-thickened areas on her chin. Debra is a 22 year-old, who has had facial hair for 8 years, scored the maximum score of sixteen. This indicates that she identifies as having thick and heavy growth on her upper lip, chin, sideburns, and lower jaw and neck. Ann is a 49 year-old, who has had hair for 10 years, had a score of two. She identifies as having sparse terminal hairs with small-thickened areas on her chin. Kim, who is 67 years old, has had facial hair for ten years or more. She scored an eight, indicating that she has sparse terminal hairs on her sideburns, lower jaw and neck, a moustache covering fifty percent from the outer margin of the lip or fifty percent of the lip height, and light growth covering the chin. Kiesha, who is 49 years-old and has had facial hair for nine years, had a score of four. This self-rated score represents a thin moustache covering less than fifty percent of the upper lip or outer boarder and sparse terminal hairs with thickened areas on the chin. The stories of the participants with the lower scores did not seem to differ from those who selfidentified as having more extensive facial hair. 


\section{Data Analysis Process}

\section{Gathered stories}

The data analysis process began with the gathering of the participant's story. van Manen (1997) includes investigating experience as lived rather than as conceptualized as one of the six interrelated activities to guide the researcher in the collection and analysis of the data. This was achieved by the researcher actively exploring all aspects of the lived experience (van Manen, 1990). The researcher remained present and attentive as the participant shared her experience. The researcher used field notes to prompt the need for clarification from the participant as well as to encourage the participant to explore the experience as it was lived.

Story theory provided the groundwork for engaging in intentional dialogue. This framework is necessary to fully investigate experience as lived (Smith \& Liehr, 2014). At the beginning of the interview the participants were asked, What is it like to presently live with excess facial hair? The participants were prompted to explore their current experience in relation to their thoughts, feelings, actions, and relationships with others. With these same constructs in mind the participants were asked to take the researcher back to when they first noticed that they had excess facial hair. Lastly the participants were asked to explore how they forecasted excess facial hair impacting their future thoughts, feelings, actions, and relationships with others. The participants were encouraged to divulge as much information as they chose to share.

\section{Reconstructed stories}

The next step in the data analysis process supported van Manen's (1997) activity of describing the phenomenon through the art of writing and rewriting. The researcher transcribed each taped interview into written form as she listened intently. Once the interviews were transcribed verbatim, the researcher used the gathered data to reconstruct the story for each 
participant. As Smith and Liehr (2014) described, each story was reconstructed with a beginning, middle, and end through the voice and lens of the participant. The researcher was careful not to interject her own thoughts and feelings into the participant's story by only making changes to grammar and syntax when warranted.

\section{Validated reconstruction}

As part of secondary data collection, while sharing initial findings with participants, an additional question was asked to clarify the African American woman's experience with excess facial hair. Results will be presented at the end of the chapter.

\section{Identified essential statements in each story}

Following van Manen's belief that when a person shares a story there is always something to be gathered, the researcher began the task of identifying essential statements. The selective reading approach was utilized in order to identify essential statements in each story (van Manen, 1990). The researcher read each individual story with the question in mind, What statement(s) seem particularly essential or revealing about the experience of living with excess facial hair? The researcher then underlined and highlighted statements that revealed the participant's thoughts, feelings, or actions surrounding living with excess facial hair.

\section{Raised statements to core qualities}

The researcher, through scholarly discourse with an expert qualitative research faculty mentor, lifted essential statements to form abstract core qualities. This scholarly discourse included the action of writing and rewriting. The statements from each story were initially examined with the question, What is this about? The researcher then wrote a description for each statement that captured what the participant had conveyed. Through this task some statements, previously identified as essential, were omitted due to the fact that they did not project a 
substantial contribution to structuring the meaning of what it is like to live with excess facial hair. The remaining substantive statements were then grouped into like categories based on the answer to the question, What is this about? At this point, statements were no longer being analyzed as individual statements. The researcher moved to viewing the statements as a whole composition that included all of the statements from the stories. Through this intensive and reflective undertaking, five core qualities were identified: (a) realizing the problem, (b) maintaining acceptable appearance, (c) relating with others, (d) facing an image of self, and (e) settling with an impending fate.

\section{Synthesized qualities to reveal themes}

The final step of analyzing the data involved a detailed interpretive synthesis of the data. As previously mentioned in chapter three, a theme is the focal point of meaning captured by the researcher through interpretation (van Manen, 1997). The identified themes are essentially the building blocks of the structure of meaning. The interpretive synthesis began with placing the descriptive statements under each core quality. The participant statements continued to be analyzed as a whole composition in relation to the core qualities. These essential components were grouped together and the researcher asked the question of the collective, What does this say about the experience of living with excess facial hair? As a result of this inquiry five themes that make up the structure of meaning were explicated.

\section{Study Findings}

The structure of meaning of living with excess facial hair for African-American women is: (a) encountering a repugnant revelation detected by self and others; (b) exercising the obligation to tweeze, wax, thread, shave, or conceal in an attempt to control the uncontrollable; (c) discerning a self-imposed response to others' words and actions; (d) bringing to the forefront 
disapproving thoughts and feelings of being masculine, unattractive, and embarrassed; and (e) making up one's mind to accept that which cannot be changed.

The structure of meaning of living with excess facial hair for African-American women that developed from this study is comprised of five themes that were derived from the five core qualities. Each theme is equal in its exemplification of the structure of meaning. However no one theme in itself can represent the full meaning of what it is like to live with excess facial hair. The researcher identified participant exemplars that best reflect each theme of the structure of meaning. A description of the data using these exemplars is presented below.

\section{Encountering a repugnant revelation detected by self and others.}

All of the participants described how they came to know that they had hair on their faces. Three of the participants had their facial hair pointed out to them by other people, while the other five discovered the hair for themselves. All of the participants described their feeling toward realizing that the hair was on their face with words of disdain. Nikki described her experience of having her facial hair brought to her attention by strangers:

It wasn't until I was in the barbershop one day with my son, that I realized it was a problem. I thought it was kind of sexy, people used to say women with a little hair on their lip was sexy, so I didn't think anything of it, but I heard a man talking to another guy. They were talking about me, like "Yo we need to get her in the chair". Hearing that kind of hurt my feelings. They didn't know that I heard them and they were laughing about it. Then I started looking at pictures of myself and realized how it had gotten thicker and thicker over the years; and that it was starting to look bad, more noticeable. Another participant Kiesha came to the realization that she had excess facial hair as she had a discussion with a friend: 
About nine years ago I was talking to this girl who knew a mutual friend of mine and when she was telling me she said, "Yeah he said he knew you. And I asked him what girl is it? And he said the one with the mustache." Before she had told me that this was how he identified me I didn't know notice that I had facial hair. I was embarrassed that that was how someone identified me.

While Tina's hair was brought to her attention by someone who was providing her with a facial service:

Initially my hair was pointed out to me by an esthetician when I was getting my eyebrows waxed. She pointed out the hair on my chin and asked if she could wax it and I told her "No". At that time she just plucked it, she pulled it with tweezers. I was surprised definitely that I had hair. Then when a few more started growing in I was concerned, borderline worried.

Debra who was the youngest participant described her reaction as well, as her interaction with her mother once she identified the facial hair for herself:

I was 16 years old when I noticed the hair growth. Oh my goodness, I cried about it every day, I cried and I cried and I cried. I said, "Mom look at this. What is this? She said, "Debra you are a beautiful girl, don't worry about that. Don't worry at all." She said, "Don't worry about that you are fine." I said, "Ma it is easy for you to say because you don't have any hair on your face.

Overall, the participants were able to identify when they first came to know that they had hair on their face. The stories of these women suggest that the revelation that they had excess facial hair came with feelings of embarrassment, sorrow, and uneasiness. As more hair grew the level of dislike that the women had toward the hair grew as well. 


\section{Exercising the obligation to tweeze, wax, thread, shave, or conceal in an attempt to control the uncontrollable.}

Overall the participants described the various methods that they used to control a problem that they ultimately found that they had no control over. As the hair continued to grow some of them would hide the hair with make up or scarves, in addition to participating in a ritualistic grooming process that removed hair temporarily.

Debra describes the negative impact that her grooming process and acts of concealment have on her:

Before I get dressed I have to pluck my face, I have to make sure that I don't have hair showing, my sideburns are clean, I don't have chin hairs, no hairs on my chin, no mustache. So it may take you an hour to get ready, it will take me about four to five hours to get ready because I need to make sure that I do not have any hair on my face. The downs include having to take five hours to get ready to make sure none of the hair is showing. To actually go through weeks on and weeks off as far as the plucking and making sure that it grows out so that I can pluck it. Just the fact that I have to let it grow back in order for me to pluck it brings me down. The hiding with the scarves, the going in public and people noticing are down moments.

Another woman, Ann, describes her plucking ritual:

It is something that can be seen and if I don't pluck them out on a daily basis, sometimes twice a day you can actually see that it's like I'm growing a beard. It takes about 5 to 10 minutes sometimes twice a day. Sometimes I do it in the morning and at night.

Similarly to Ann, Kim notices hair both day and night. Kim describes her grooming process: 
I initially pulled them out. I never thought that was something that needed to be on my face, neck and décolleté. I thought, "You got to go." So I plucked it or shaved it and I still do and I got some under here that need my attention because they also get hooked in your clothes. They stick in your skin and get hooked in your turtle necks, and maybe even in your jewelry if it is long enough. So that's a no no. Normally if I don't leave the house, if I have hair, I do not shave. I almost always have some growth. It comes back over night. In the morning like when I go to church when I take care of it, at night I have hair on my face again. But if I don't leave the house normally I don't shave. If I am going to choir rehearsal, doctor's appointment, or church I have several devices that I take hair off my face with. Some of them get the job done better than others. I use those little disposable razors. I guess Bic is what they call them. I have a real shaver, I even will try my trimmers that I do my neck and around my ears with. It depends, but when I go out I want to make sure that my face is devoid of hair. And I forgot tweezers, I use tweezers too, but that is too much trouble and it takes too long. When I use a razor or a shaver I can get the job done. It cuts it very short it doesn't take it away like tweezers would, but it is faster and I can just handle more hairs. I shave it all with my various devices and then I rub it. I shave against the grain and I shave with the grain. I take care to tighten up before I leave the house.

Lisa was the only woman who sought the help of a dermatologist to control her excess facial hair. In addition to her grooming process, she speaks about the various treatments that were prescribed by a physician:

First thing in the morning I'm up and I'm examining my face making sure I don't have any chin hairs before I go out. I also make sure that I don't have a woman stache 
a.k.a. a mustache. If I do I'm plucking and putting baby oil on it and trying to make my face look presentable. I pull on my skin tightly, get tweezers, dip it in Seabreeze and I'm plucking out the hairs in the morning. Then I massage my skin with baby oil.

When I went to the dermatologist, to present my problem, he asked me when I went there, "Do you put a razor to your face? I said "Yes." He said, "Women shouldn't do that. When you start using a razor to your face you cause ingrown hairs and black heads and scarring on your face". I had gone to the dermatologist because the ingrown hairs were coming up and I was getting all these black marks on my face and chin. Before I used to be able to use a dab of concealer to hide what was going on. I found myself having to use more and more of it and I'm not the type who uses make-up. What you see is what you get. On my black pimples, hair pimples I use Fashion Fair concealer. I just use a small amount on my baby finger and I dab it on and massage it in until it blends in with my skin color.

Right now I'm going to the dermatologist and he gives me this cream that once I have my waxing or threading done I'm supposed to put on immediately so that it won't cause any kind of infection. The cream that he gave me it's for bacteria, so that I won't get bacteria. When I get my waxing or threading done once they take the hair off I tell them, "Hold up I need to put my little cream on my face that the doctor gave me." The feeling of not being able to control the uncontrollable was evident in all of the women's stories. This was highlighted by descriptions such as: “Aggravation leads her to thoughts about permanent resolution to the relentless, incessant hair growth that is unfazed by removal"; "Constant vigilance on keeping skin free of hair by having a razor close by at all 
times"; "Unrelenting time-consuming plucking is disheartening"; and "Despite removal efforts the hair continues to grow."

\section{Discerning a self-imposed response to others' words and actions.}

The participants revealed that they respond differently to the words and actions of those whom they have relationships with and those whom they encounter. Lisa describes her response to her husband's inquisition concerning her hair, as well as her response to a friend who also has hair:

One day on the way to church I was driving, and my husband looked over to me and said "Baby did you shave today? I felt humiliated he pulled out his razor and I took his razor, a dry razor, and I was shaving hair off my face...My husband he's going to love me regardless so it doesn't bother him. Sometimes he jokes around and when he jokes around it hurts my feelings. At one point my husband used to tickle me under my chin and now if I see his hands going that way I stop him instantly, I tickle his face, and we play it off.

I have coworker who I share what I am going through with because she suffers with the same thing. We talk about different remedies and things that we do and she also gets waxing once in a while. I guess we do the same thing with the waxing, and plucking with tweezers. She and my husband are the only two who ever say anything about my hair. It is a personal joke between she and I, “Oh you didn't do your face this morning. Oh I got my tweezers with me I'm going to go in the bathroom and do it." Then we hear the clicking of the tweezers on the sink and look at each other like, "Oh how many hairs I got today? With her it is just one hundred. We keep it one hundred with each other. We 
are just open and honest. Maybe she is doing something that can help me and maybe I can do something that can help her.

One other participant, Ann, revealed how she feels when her husband comments on her hair, "My husband teases me and asks, “Are you shaving again? But as far as I know it doesn't bother him. He has never really said anything about it bothering him. I feel uncomfortable when he jokes about it."

Other participants revealed how they feel and respond when others whom they come in contact with comment or stare at the excess facial hair. Nikki describes her interactions with others:

I am very, very self-conscious of it, and very aware of it to the point where I don't really get close to people. When cheek to cheek hugging, or if someone looks like they are going to attempt to rub my face that is the first thing that I think about. Can they feel stubble? This happens often because of my work environment, family environment, and being involved in ministry. I am constantly in a lot of social environments and hugging is the way I usually greet people. When I walk away I am like, "Ooh I hope they did not feel my stickers or my mustache, or see my visible things like razor bumps and the dark spots". I kind of put my chin down, and things like that. I am always aware especially if I am directly face to face with someone; I'm even more conscious of where his or her eyes are going. So it is constantly on my mind.

While other participants such as Debra find themselves isolating herself from friends and the public:

I isolate myself during the periods when I let my hair grow back, and sometimes I am just really down. I remember when I first, first started to grow my hair. And sometimes I 
would even skip school. I wouldn't want to go to school with my hair. I isolated myself. I wouldn't go out. All of my friends would go out and I was like I will stay home. I didn't go out for about two or three years. I didn't want to go out. I did not want to be seen in public.

Debra went on to describe how she reacts when she is beginning to form a new relationship with a man whom she is interested in dating:

I would hide it. I would hide it. I never let anyone really get close to me as far as the hair. I would definitely try to hide it and if he noticed it I wouldn't talk to him anymore. I was dealing with this guy and we went out on a date and he noticed that I had chin hair. He didn't say much about it, but I knew that it kind of bothered him. He didn't say much about it so I asked him how he feels about a woman with hair and he told me that he did not care for it. Like he thinks that it is the most unattractive thing ever. So after that conversation it was done, I didn't want anything to do with him because I knew that he was not going to accept the fact that I have hair. Granted I wasn't born with it. It was something that happened over a period of time, but it was something that he couldn't deal with. So, I just didn't, I said, "No hell with it, hell with him”, and moved on.

Whenever I am dating someone that I am interested in I always ask him how he feels about hair. I always ask them how they feel about hair, because I tell them I am a hairy woman. When you see hair on a part of my body that shouldn't be, don't be alarmed because I am a hairy woman, so I don't show them where the hair is, but I let them know that I am hairy. Like I said I wear these scarves, and I pluck it, because when I pluck it, it doesn't look like I have any hair. So I try to not date on the weeks that I let my hair grow back. So I do a good job with hiding it. 


\section{Bringing to the forefront disapproving thoughts and feelings of being masculine, unattractive, and embarrassed.}

All of the women expressed that having excess facial hair led them to feel like they looked like a man and they were unattractive. This is an issue for them. This concern is captured in statements like the ones expressed by Tanya, "If I see them it is a problem because I don't want to look like a man” and Kiesha, “I think I look like a man. I just associate hair growing on your chin, under your nose, on top of you lip with men. That is what men have mustaches and beards". The thoughts and feelings related to looking like a man and being unattractive are captured in Kim's description of how she feels:

I don't feel as feminine, attractive, or as well groomed... a part of my regimen is shaving so that I don’t look like a man. ). I really don’t think I am well groomed and I have the whole package until I shave. Yes, that's it I think that it is masculine looking to have hair on your face. It really is just like a man.

Likewise, Debra expressed her thoughts stating, "When I think of my mustaches and my hair I think ugly, I think of everything possible, ugly, hideous, men, a man. I just think of so many negative things". Tina revealed the steps that she takes in an attempt to preserve her femininity, in addition to her embarrassment as well as disdain for the hair:

As a female having facial hair is embarrassing to me. I'd rather it not be there. I just don't want it. I try to make my face up and put a little makeup on and that kind of takes away from the makeup. I think the hair takes away from my makeup. It is not a very attractive feminine feature. On a man that's one thing, but not on a female. In concert with believing that excess facial hair is masculine, all but one of the participants used some form of the word "embarrassed" to describe how they felt about the hair 
at some point in their life. For Lisa her embarrassment was expressed following her initial revelation that she had hair, "I wondered what was going on with me. Is this a part of getting old? I just really found it embarrassing". Kiesha also used the word "embarrassed" to describe how she felt when the word "mustache" was used to describe her, "I was embarrassed that that was how someone identified me." Ann also described how she currently feels about the hair, "To presently live with excess facial hair is embarrassing."

\section{Making up one's mind to accept that which cannot be changed.}

By the end of her story, each participant reached some form of resolve related to living with excess facial hair. All of the participants acknowledge that they will have excess facial hair for the rest of their lives. However only one participant, Tina, remained hopeful that she one day would be able to afford a relatively permanent solution if her hair problem progressed:

Hopefully I will be able to get laser hair removal one-day. When I find a facility that is a little more accommodating to my economic status at that time in costs. If I can find something lower I might undergo laser hair removal. I'm definitely not going to shave I will just continue threading until then. And I'm going to hope that nothing else grows in. I will feel like I need to save my money and get more money together if more hair starts to grow in, so that I can go ahead with the laser treatment faster. It would become more of a priority.

Other participants acknowledged and accepted that they will continue to carry out their present day regimen to remove the hair. Lisa described her desire for things to change, fear that things will worsen, and intention to keep things the same:

I wish I will wake up one morning and it be gone. I would say, "Hallelujah.” I would be so happy, happy, elated, joyful the list goes on and on. I'd be thankful. My fear is that it 
is only going to get thicker. I want my skin complexion to come back I don't want this ugliness under my chin. I've never had this before I used to be called mocha, creamy caramel chocolate, and I want that back. Not these raisins and bumps. I don't see me changing anything in the future. I'll just do the regimen that the doctor has given me. I'll just keep doing what I'm doing. It is what it is.

Ann shares Lisa's fear of the problem worsening and forecasts that she may have to resort to more aggressive hair removal methods:

I do believe that in the future it is going to be a problem. I believe as the years go by it will get worse because right now it is taking me a long time to even pluck them out. So in about 5 to 10 years I may be even using a razor. I think that's going to be the hard part because then you end up getting razor bumps and all that kind of stuff. That I don't want. An alternative to shaving would be a commercial on television that I saw one-time, and I was like "I ought to buy that", but I was scared too. It was a "NoNo", it was some type, I believe, of laser that you put on there and it takes the hair off. I was thinking about buying one of those, but I was afraid because I didn't know what it was.

Three of the participants expressed fear that as they progress in age, they will not be able to maintain their current hair removal regimen for themselves. Nikki has expressed to her children what they should do in the event that she falls ill:

If I am sick or whatever so, some people think that it is funny or it is vanity, but to me it matters to me. Even if I am unconscious, don't let me look like that. That is how much it matters to me. So the kids know, in fact we even joke about it, like y'all know what y'all are supposed to do if I get sick, and they are like, "I know I know, shave your chin". 
While Kim shares Nikki's sentiments she has not told her children her wishes, but her story revealed what she would like them to know:

If I ever get to the point where I am not taking care of my whole body, it is because I can't. It is because I don't realize that something is out of order, or unlike me. I have absolutely lost my mental faculties. There is no way in the world I would do that on purpose, that is like smelling and not wanting to do anything about that.

I have not had this conversation with my daughters or granddaughters. But I would say to them if there was an occasion when my program was out of order, "Please don't let me, please don't let me go out like that. I would have been mortified if I knew that I didn't have a shave and some Vaseline on my skin and I smelled. Don't let me go out like that because that is not who your mother has been all your life". Maybe I will get to the point where they don't want me to have a razor, or don't trust me with a razor, maybe that's why some of those old ladies don't shave the hair off. I don't know, but I just think that it looks bad.

Similarly, Tanya had not previously shared her fears of the future with anyone else prior to her interview, but expressed that she is frightened by the thought that in the future she may be unable to remove the hair herself:

I see more of them coming and I don't want them to come in. I am over fifty I don't want to be one of those women, in the future. I've seen women who just have hair growing out of their neck and chin and I don't want to be one of those who can't get to it to clean it up, and that kind of scares me. Becoming one of those women is a scary thought for me. 


\section{Validation of stories}

A follow up interview was conducted with each participant to have her read and reflect on her reconstructed story. Each participant was asked to read the story to herself and once completed she was asked, tell me how this captured your story. All of the participants responded similarly. Responses ranged from a simple, "This is my story”, and "It captures my story accurately" to Debra's more elaborate response:

It talks about all of experiences from feelings to isolation to the things that I go through with plucking my hair, my relationships. It touches on mainly my everyday thoughts about it. It captured everything from beginning to end. From when it first started until now.

and Nikki's more descriptive statements:

I can see, when I read this going back, I can see a transition in here. When it starts out I can see how I felt in the beginning. But then even though it is still a problem it almost ends like it is hopeful that because of how strong I am as a person and my self-esteem helps me to actually not dictate who I am. I see growth in these four pieces of paper. I see growth from being so, so insecure, not to say that I am not still insecure and aware of it, but it hasn't taken over me. It is there, but I deal with it. I realize that I am dealing with it.

After reading their stories the participants expressed that while reading they were made aware of how having the hair really impacts them. For some participants they shared that they never realized how much having the hair really impacted them. Other participants shared that they fully related to what they had read. Debra had a major revelation after reading her own 
story and realized something that she shared in the moment of sharing may not really be her truth:

One thing that stuck out the most is when I said if the world was okay with it I would be okay with it. And when I think about it I don't even know if that is even true. It is one of those things where emotionally, not even emotionally, it is one of those things when you have to be confident in yourself. You have to definitely love yourself regardless of any picture that anyone tries to paint of you, or anything that is going on. You have to love yourself first. It was something else that I said. Being around people who accept you for you that plays a big part whether is family, close friends or your significant other. Being around people that accept you for you. It is not so much the world I guess just involving yourself and surrounding yourself with people who are interested in how you feel and the feelings that you have whether it is from hair to the way you look or the outfits that you wear. Just being comfortable in your own skin regardless of what anyone thinks. It is difficult, but it is a profound statement you have to be comfortable with you. You have to love you. Nobody can, I honestly feel that no one can validate who you are. Nobody can make you love yourself. That is something that comes from within. So with my hair and everything I had to learn to love my hair because I love me. It is a part of me so I had to learn how to accept it and love it. I just hope that this will be looked at seriously and that something would be done about it. The participants were also asked what it was like to share their story and expressed an assortment of emotions related to being able to share their story. Some felt that it was more difficult to share than they thought it would be; while others felt that it was refreshing to realize that conducting this study meant that they are not alone when dealing with excess facial hair. 
Although some of the participants expressed that sharing their stories were painful or difficult they all denied the need for counseling or psychological evaluation.

After obtaining feedback on the reconstructed stories, the participants were then asked, "Tell me how having excess facial hair impacts you specifically as an African-American woman." The results of this follow up represents an African American perspective.

\section{An African-American perspective}

When asked to describe the impact of excess facial hair as an African American woman, they generally believed that having the excess facial hair was a problem faced by women of all ethnicities. However, many of the women revealed that having excess facial hair impacts African-American women differently than those from other cultures. Nikki expressed that the features of African-American women don't fit the world's perception of beauty and for that reason having the hair adds an extra challenge. Tina shared a view similar to that of Nikki's. Tina believes that having excess facial hair adds another layer to the societal burdens faced by African-American women.

Some of the other women took a different approach and shared more specific views of the impact on African-American beauty and grooming. Lisa expressed that soft, creamy complexions symbolize African-American beauty and that having excess facial hair detracts from this beauty. Ann revealed that for African-American women appearance means everything and that having one abnormal feature impacts how one feels about self and how self is presented. Furthermore, in the spirit of presentation of self, three of the remaining participants believed that as children their parents taught them that they should be well groomed. They all similarly shared that their mothers taught them to make sure that they were well put together before revealing themselves to the masses. This included making sure that they were clean and that their clothes 
were neat, but as they got older and started growing the facial hair they naturally added this to their definition of being well groomed.

Debra was the only participant who spoke of having excess facial hair as an AfricanAmerican woman in relation to other African-American women. She voiced that she feels like having the hair sets her apart from other African-American women. She also expressed that there are a lot of things that are worst than having excess facial hair that African-American women face. Therefore, she is grateful that she only has too much facial hair.

Having the participants answer this additional question adds another layer to the developed structure of meaning. It does not change the structure of meaning, but provides insight into the way participants are presented to the world and how they feel about themselves. These findings emphasize the importance of body ethic to African-American women.

\section{Summary}

The research question for this study was, What is the structure of meaning of living with excess facial hair for African-American women? van Manen's hermeneutic phenomenology and Smith \& Liehr's story theory were used as frameworks for data collection and analysis. The reconstructed stories were developed from the participant's recorded interviews. The validated reconstructions were then analyzed for essential statements. The essential statements were analyzed as a whole composition and raised in their level of abstraction into core qualities. The descriptives of the core qualities were developed into the themes that in turn served as the building blocks of the structure of meaning for African-American women living with excess facial hair.

The structure of meaning for this study on living with excess facial hair for AfricanAmerican women is: (a) encountering a repugnant revelation detected by self and others; (b) 
exercising the obligation to tweeze, wax, thread, shave, or conceal in an attempt to control the uncontrollable; (c) discerning a self-imposed response to others' words and actions; (d) bringing to the forefront disapproving thoughts and feelings of being masculine, unattractive, and embarrassed; and (e) making up one's mind to accept that which cannot be changed. Reflections on the impact of facial hair for African American women were also presented. 


\section{Chapter 5: Discussion}

The purpose of this study was to describe the structure of meaning of living with excess facial hair for African-American women. The study was guided by the question, What is the structure of meaning of living with excess facial hair for African-American women? van Manen's (1997) description of hermeneutic phenomenology and Smith and Liehr's (2014) story theory served as the philosophical underpinnings for the study. As noted in the previous chapter the structure of meaning of living with excess facial hair for African-American women is: (a) encountering a repugnant revelation detected by self and others; (b) exercising the obligation to tweeze, wax, thread, shave, or conceal in an attempt to control the uncontrollable; (c) discerning a self-imposed response to others' words and actions; (d) bringing to the forefront disapproving thoughts and feelings of being masculine, unattractive, and embarrassed; and (e) making up one's mind to accept that which cannot be changed. The purpose of this chapter is to discuss the structure of meaning of living with excess facial for African-American women in relation to health-related quality of life (HRQOL) a conceptual model described by Ferrans, Zerwic, Wilbur, and Larson (2005), story theory, and the significance to nursing. Lastly, implications for research and practice will be offered.

\section{Health-Related Quality of Life}

Health-related quality of life is a concept that focuses on the impact a person's health, illness, and treatment has on the quality of his/her life (Ferrans, Zerwic, Wilbur \& Larson, 2005). Indicators of health related quality of life are biological function, symptoms, functional status, general health perceptions, and overall quality of life (Ferrans, Zerwic, Wilbur \& Larson, 2005). Biological function impacts symptoms, symptoms impact functional status, functional status impacts general health perceptions, and general health perceptions impact overall quality of life 
(Ferrans, Zerwic, Wilbur \& Larson, 2005; Wilson \& Cleary, 1995). The findings of this study are related to functional status, general health perceptions and overall quality of life for women with excess facial hair.

\section{Functional status}

Functional status is a multidimensional concept defined as the ability to perform a task (Wilson \& Cleary, 1995). Functional performance, a dimension of functional status, is the activities that one performs daily in an attempt to meet basic needs, fulfill usual roles, and maintain health and well-being (Leidy, 1994). One of the themes in the structure of meaning is exercising the obligation to tweeze, wax, thread, shave, or conceal in an attempt to control the uncontrollable. The women in this study described that they participate in daily, weekly, or monthly regimens to maintain a feminine appearance. Tweezing, waxing, threading, and shaving are activities included in their regimen. One participant shared that performing her shaving ritual is like maintaining her health. Several other participants used the word grooming to describe this activity of daily living. Some of the women in this study used make-up and objects like scarves to conceal their facial hair. Keegan et al. (2003) labels this process of removing hair to fit in with societal norms of femininity as passing. For these women these functional activities allow them to fulfill their roles as women when facing the outside world, in spite of the time, money, and effort needed to maintain their functional status.

\section{General health perceptions}

General health perceptions are subjective responses that serve as an integrated representation of biological and physical factors, symptoms, functional status, and mental health (Wilson \& Cleary, 1995). Three themes in the structure of meaning are related to the concept of general health perceptions: These are: (1) encountering a repugnant revelation detected by self 
and others; (2) discerning a self-imposed response to others' words and actions; and (3) bringing to the forefront disapproving thoughts and feelings of being masculine, unattractive, and embarrassed.

The first theme, encountering a repugnant revelation detected by self and others, represents the strong emotions expressed by women in this study related to the realization that they have facial hair. Symptoms, which are defined as "a patient's perception of an abnormal physical, emotional, or cognitive state" have a direct impact on general health perceptions (Wilson \& Cleary, 1995, p. 61). The women in this study all identified the excessive facial hair as an abnormality. Most of the women indicated that having excess facial hair was an embarrassing health challenge. The women also expressed an increase in their level of disdain as the facial hair worsened.

The second theme, discerning a self-imposed response to others' words and actions, is a subjective response to those whom they encountered. Social environment has an impact on general health perceptions (Ferrans, Zerwic, Wilbur \& Larson, 2005; Wilson \& Cleary, 1995). Two of the women described the comments made by their husbands as embarrassing. Contrarily, one of these women described the comments by one of her coworkers, who also has excess facial hair, to be acceptable. This contrast in response gives insight into how co-experiencing living with excess facial hair changed the participant's perception of the health challenge.

The third theme, bringing to the forefront disapproving thoughts and feelings of being masculine, unattractive, and embarrassed, encompasses the women's general regard for having excess facial hair. The women in this study revealed that they believe having excess facial hair is masculine and unattractive. This finding is similar to Kitzinger \& Willmott's (2002) finding that women reported feeling freakish, abnormal, and not proper. Keegan et al. (2003) reported 
like findings of women feeling as though facial hair demarcates masculinity and femininity. The descriptive words used to portray thoughts and emotions related to excess facial hair reveal the negative perception that all of the women generally have toward this health challenge related to the quality of life dimension of general health perceptions.

\section{Overall quality of life}

Overall quality of life is an indicator of subjective well-being related to how happy or satisfied one is with life as a whole (Wilson \& Cleary, 1995). Personal values, expectation levels, aspiration levels, personal needs, and comparisons with others are all internal standards that impact one's level of life satisfaction (Campbell, Converse, \& Rodgers, 1976). According to Diener, Suh, Lucas, \& Smith (1999) subjective well-being includes pleasant and unpleasant affect, global judgments of life satisfaction, and satisfaction with individual domains of life. The theme, making up one's mind to accept that which cannot be changed, speaks to the participant's resolve to be satisfied with an unpleasant aspect of her life. The women in this study revealed that having excess facial hair is a component of life that they wish would go away, but understand that this wish will more than likely never come to fruition. In light of this revelation the participants in this study expressed that they will continue with current regimens, begin new regimens, or enlist the help of others to maintain a hair free appearance. This diligence to conceal their excess facial hair in the future reveals the participants' present level of dissatisfaction with this aspect of their lives. It has been established through prior studies that quality of life improves when women have a noticeable reduction in the amount of facial hair that they have (Wong \& River, 2009; Maziar, 2010; Conroy, et al., 2006). Quality of life also improves when women do not have to continue to carry out their facial hair regimen (Clayton, et al., 2005). 
The structure of meaning for African-American women living with excess facial hair can be related to the concept health related quality of life (Ferrans, Zerwic, Wilbur \& Larson, 2005; Wilson \& Cleary, 1995). Health related quality of life offers a conceptual framework for further understanding the structure of meaning of living with excess facial hair. Functional status, general health perception, and overall quality of life are interrelated with the findings of this study.

\section{Story Theory}

Story theory is described as a "narrative happening of connecting with self-in-relation through intentional dialogue to create ease" (Smith \& Liehr, 2014, p. 229). There are three story processes related to the concepts of the theory. These are the complicating health challenge, developing story plot, and movement toward resolving (Smith \& Liehr, 2014). The processes will be discussed as they relate to the findings of this study.

During the story gathering process the participants were engaged with the researcher who was intentionally present to listen and query their story of the complicating health challenge, of living with excess facial hair. Given the stories, the participants allowed themselves to be open and honest with the researcher about their complicating health challenge. For many of the participants the researcher was the first person to whom they had ever revealed the full story of living with facial hair. This response is related to the theme, discerning a self-imposed response to others' words and actions. The women's usual response was to question if others had noticed their hair, isolate themselves so that others would not see their hair, or be embarrassed about others noticing their hair. None of the women expressed feeling embarrassed or ashamed about telling her story to the researcher. The women chose to respond openly to the opportunity to tell their story. 
The description of the developing story plot is the inclusion of critical issues in the story (Smith \& Liehr, 2014). The developing story plot in this study is related to the following themes: (1) a repugnant revelation detected by self and others; (2) exercising the obligation to tweeze, wax, thread, shave, or conceal in an attempt to control the uncontrollable; and (3) bringing to the forefront disapproving thoughts and feelings of being masculine, unattractive, and embarrassed, are all pivotal in understanding the story plot.

The first theme, encountering a repugnant revelation detected by self and others, serves as the exposition of the story plot. It is after the excess facial hair was brought to the woman's attention by someone else, or discovered by her, that having excess facial hair became recognized as a beginning story plot. The notion that having the facial hair was objectionable set the tone for the actions and emotions experienced by the women.

The second theme, exercising the obligation to tweeze, wax, thread, shave, or conceal in an attempt to control the uncontrollable, helps one to understand the measures that these women take to intervene on their own behalf. This theme is critical to the development of the story plot. It allows one to have insight into the day-to-day lives of these women. For these women engaging in activities to control the hair that will inevitably return is not a choice, but a necessity. This theme embodies the demand that having excess facial hair places on the women.

The third theme, bringing to the forefront disapproving thoughts and feelings of being masculine, unattractive, and embarrassed, similar to the second embodies the psychological demand that having excess facial hair places on these women. For that reason, this theme is critical in the sense that it gives understanding of the significant attention that women with excess facial hair bestow upon this issue. For the women in this study feeling masculine, 
unattractive, and embarrassed were primary revelations and emotions that they experienced as the story plot developed.

Movement toward resolving includes the actions described by the storyteller that led to resolving the complicating health challenge (Smith \& Liehr, 2014). Movement toward resolution is implied in the theme, making up one's mind to accept that which cannot be changed. This theme captures the understanding that all of the women expressed at the end of their story. Although some of the women describe more intensive actions that they will take to control their hair in the future, all of the women acknowledge that having facial hair will be a part of them for the rest of their lives. None of the women expressed that the health challenge will ever be completely resolved, but they all reached a place of accepting that excess facial hair as a part of life.

Story theory served as one of the theoretical underpinnings for gathering the stories of the eight women who participated in this study. The researcher's purposeful engagement and true presence allowed the stories to unfold. The five themes that emerged through the story gathering process exposed development of the story plot and revealed the resolution of the complicating health challenge.

\section{Significance of the Findings to the Knowledge Base of Nursing}

This study addressed the question, What is the structure of meaning of living with excess facial hair for African-American women? Exploration of this research question generated an understanding of the human health experience through the lens of African-American women. The findings of this study revealed themes of the structure of meaning of living with this human health challenge. It is believed that these findings make a significant contribution to the knowledge base of nursing. 
Reconstructing meaning as lived by the patient is essential in this postmodern era of nursing knowledge development. According to Watson (1995), "the postmodern truth for nursing reconnects with the truth of unfoldment, an expansion and fusing of horizons of meaning" (p.63). The question of the importance of the findings of this study is located in the structure of meaning. The structure of meaning gives insight into how having excess facial hair impacts the participant's relationships, thoughts, feelings, and actions. As nursing continues to shift from analytical to artistic dimensions of knowledge development, constructs describing the human health experience are essential (Watson, 1995).

This study captured the essence of meaning of living with excess facial hair from African-American women and produced a structure of meaning that is based on the rich descriptions from these women. This structure of meaning gives insight into some of the possible aspects of these women's lives that may contribute to the expression of concerns including controlling an aspect of life in which they lack control over. Culture sensitivity is an important aspect of patient-centered care. The findings of this study on living with excess facial hair as an African-American woman may contribute to the knowledge base of cultural sensitive care. Gaining this understanding in the context of developing the structure of meaning through narrative captured the wholeness of the human experience (Donaldson \& Crowley, 1978).

\section{Implications for Research}

The structure of meaning developed in this study indicates that having excess facial hair can impact the health related quality of life of African-American women. This study laid the foundational groundwork necessary to further explicate the phenomenon. The structure of meaning may provide the basis for further development of research questions. Qualitative studies focused on the impact of facial hair on the various domains of health related quality of 
life could be developed. Developing a study using the health related quality of life conceptual model, as a descriptive framework would show the way women describe biologic function, symptoms, functional status, general health perceptions, and overall quality of life in the context of excess facial hair. Content analysis of the descriptions would offer another perspective on living with excess facial hair. In addition to the utilization of qualitative methodologies a mixedmethods approach may be beneficial in which quality of life is measured alongside the gathering of participant narratives.

Current literature focuses on excess facial hair as a symptom of underlying conditions such as polycystic ovarian syndrome. None of the women in this study had a known underlying cause for their excess facial hair. This lack of diagnosis may indicate a need for future research to specifically focus on excess facial hair in the absence of a known disease process. Designing a study with health care providers as subjects to query the way in which they treat women with excess facial hair may also be warranted. The findings of this study made it evident that even the women who do not know why they have facial hair are impacted by the presence of excess facial hair.

The willingness of each woman to share her story openly and honestly highlights her desire for others to know what it is like for her to live with this complicated health challenge. All of the participants were African-American. Larger studies that ask the same question of women with other racial/ethnic backgrounds, across socioeconomic groups should be developed to understand what is like for all women who have excess facial hair. Interventions to reduce excess facial hair do exist for women of varying races and ethnicities. Gathering the stories of women who complete hair reduction treatments before and after the intervention would shed light on the change in health related quality of life that takes place with the reduction in excess 
facial hair. Obtaining this data would potentially influence not only nursing practice, but also the entire health care delivery system by bringing to the forefront the need for intervention.

\section{Implications for Practice}

The findings of this study have implications for clinical practice. Nurses in various settings may encounter African-American women with excess facial hair. The themes of the structure of meaning could be used to assess women living with excess facial hair. For example, assessing a woman's face for hair and bringing it to her attention in a caring way that engages her to describe her thoughts and feelings begins the discussion about if she herself has noticed it as well as what she plans to do about it. Armed with the knowledge of the findings from this study the nurse is equipped to work with the woman through her experience. In caring for women who acknowledge the increased facial hair, the nurse may invite her to address the facial hair issue as well as the time that it takes her to remove the hair. Querying pain and discomfort may also be a component of this nurse-patient interaction. The nurse is also equipped to assess the woman for disapproving thoughts and feelings produced by this health challenge, and in turn provide counseling in helping the woman to identify ways to resolve the situation as best as it can be resolved.

The structure of meaning that developed as a result of this study may serve to assist nurses in developing plans of care for women living with excess facial hair. Although these women may have resolved to accept that which cannot be changed, the level of acceptance is in the context of attempting to control the uncontrollable. The nurse who is providing care for a woman with excess facial hair, who is incapacitated, is another implication. Based on the women's descriptions talking with family members to inquire if the woman has entrusted and instructed others to groom her by being vigilant to remove the facial hair may enhance the 
patient's experience during this time of incapacitation. This action has not been traditionally included in patient grooming, but as a result of this study can be acknowledged as a way to improve the patient's health related quality of life.

\section{Summary}

This study revealed a structure of meaning, comprised of five interrelated themes for living with excess facial hair for African-American women. Living with excess facial hair for African-American women is: (a) encountering a repugnant revelation detected by self and others;

(b) exercising the obligation to tweeze, wax, thread, shave, or conceal in an attempt to control the uncontrollable; (c) discerning a self-imposed response to others' words and actions; (d) bringing to the forefront disapproving thoughts and feelings of being masculine, unattractive, and embarrassed; and (e) making up one's mind to accept that which cannot be changed.

This understanding of the lived experience of African-American women living with excess facial hair emerged by following methods suggested by van Manen (1997) and story theory (Smith \& Liehr, 2014). The findings address a gap in the literature and capture the essence of the human health challenge of living with excess facial hair for African-American women that were missing from other studies. Further research is needed to underpin health policy to address women with excess facial hair. Findings of this study serve as the foundation for future research related to excess facial hair and influence nursing practice. 


\section{References}

Azziz, R. (2003). The evaluation and management of hirsutism. Obstetrics and Gynecology, 101, 995-1007.

Azziz, R., Sanchez, L.A., Knochenhauer, E.S., Moran, C., Lazenby, J., Stephens, K.C., Taylor, K., \& Boots, L.R. (2004). Androgen excess in women: experience with over 1000 consecutive patients. The Journal of Clinical Endocrinology and Metabolism, 89, 453462.

Basra, M.K.A., Fenech, R., Gatt, R.M., Salek, M.S., Finly, A.Y. (2008). The dermatology life quality index 1994-2007: a comprehensive review of validation data and clinical results. British Journal of Dermatology 159, 997-1035.

Campbell, A., Converse, P.E. and Rodgers, W.L. (1976). The quality of American life: Perceptions, evaluations, and satisfactions. New York: Russell Sage Foundation.

Clayton, W.J., Lipton, M., Elford, J., Rustin, M., \& Sherr, L. (2005). A randomized controlled trial of laser treatment among hirsute women with polycystic ovary syndrome. British Journal of Dermatologists 152, 989-992.

Coffey, S. \& Mason, H. (2003). The effect of polycystic ovary syndrome on healthrelated quality of life. Gynecological Endocrinology, 17(5), 379-386.

Conroy, F.J., Venus, M., \& Monk, B. (2006). A qualitative study to assess the effectiveness of laser epilation using a quality-of-life scoring system. Clinical and Experimental Dermatology, 31, 753-756. 
Cronin, L., Guyatt, G., Griffith, L., Wong, E., Azziz, R., Futterweit, W., et al. (1998). Development of a health-related quality-of-life questionnaire (PCOSQ) for women with polycystic ovary syndrome (PCOS). Journal of Clinical Endocrinology \& Metabolism 83(6), 1976-1987.

Dawber, R.P. (2005). Guidance for the management of hirsutism. Current Medical Research and Opinion, 21(8), 1227-1234.

Diener, E., Suh, E.M., Lucas, R.E., and Smith, H.L. (1999). Subjective well-being: Thee decades of progress. Psychological Bulletin, 52(2), 276-302.

Dixon, J.E., Hicks, B., \& Chapman, M. (1991). Psychological morbidity of hirsute women. Journal of Obstetrics and Gynecology, 11, 198-203.

Donaldson, S.K. and Crowley, D.M. (1978). The discipline of nursing. Nursing Outlook, 26 (2), 113-120.

Ekback, M., Wijma, K., Benzein, E. (2009). It is always on my mind: Women's experiences of their bodies when living with hirsutism. Health Care for Women International 30, 358-372.

Ferrans, C.E., Zerwic, J.J., Wilbur, J.E., Larson, J.L. (2005). Conceptual model of healthrelated quality of life. Journal of Nursing Scholarship 37(4), 336-342.

Fitzpatrick, T.B. (1988). The validity and practicality of sun-reactive skin types I through VI. Archives of Dermatology 124,869.

Guyatt, G., Weaver, B., Cronin, L., Dooley, J.A., \& Azziz, R. (2004). Health-related quality of life in women with polycystic ovary syndrome, a self-administered questionnaire, was validated. Journal of Clinical Epidemiology, 57, 1279-1287. 
Harrison, S., Somani, N., Bergfeld, W. (2010). Update on the management of hirsutism. Cleveland Clinic Journal of Medicine, 77, 388-398.

Husserl, E. (1970). The crisis of the European sciences and transcendental phenomenology: An introduction to phenomenology. (D. Carr. Transl.) Evanston, IL: Northwestern University Press.

Keegan, A, Liao,L., and Boyle, M. (2003). 'Hirsutism': A psychological analysis. Journal of Health and Psychology 8(9), 327-345.

Kitzinger, C., Willmott, J. (2002). The thief of womanhood: Women's experience of polycystic ovarian syndrome. Social Science and Medicine 54, 349-361.

Leidy, N.K. (1994). Functional status and the forward progress of merry-go-rounds: Toward a coherent analytical framework. Nursing Research 43(4), 196-202.

Lipton, W.J., Sherr, L., Elford, J., Rustin, M.H., Clayton, W.J. (2006). Women living with facial hair: The psychological and behavioral burden. Journal of Maziar, A., Farsi, N., Mandegarfard, M., Babakoohi, S., Gorouhi, F., Dowlatt, Y., and Firooz, A. (2010). Unwanted facial hair removal with laser treatment improves quality of life of patients. Journal of Cosmetic and Laser Therapy 12, 7-9.

McCook, J.G., Reame, N.E., Thatcher, S.S. (2004). Health-related quality of life issues in women with polycystic ovary syndrome. Journal of Obstetric, Gynecologic \& Neonatal Nursing 34, 12-20

Pate, C. (2013). The story plot of living the embarrassment of hirsutism. Archives of Psychiatric Nursing 27, 156-57.

Rabinowitz, S., Cohen, R., Le Roth. D. (1983). Anxiety and hirsutism. Psychological Reports 53, 827-830. 
Rosenberg, M. (1989). Society and the Adolescent Self-Image. Middletown, CT: Wesleyan University Press.

Shenton, A.K. (2004). Strategies for ensuring trustworthiness in qualitative research projects. Education for Information 22, 63-75.

Smith, M. J., \& Liehr, P. (2005). Story theory: Advancing nursing practice scholarship. Holistic Nursing Practice, 19(6), 272-276.

Smith, M. J., \& Liehr, P. R. (Eds.). (2008). Middle range theory for nursing (2nd ed.). New York, NY: Springer.

Smith, M. J., \& Liehr, P. R. (Eds.). (2014). Middle range theory for nursing (3rd ed.). New York, NY: Springer.

Synder, B.S. (2006). The lived experience of women diagnosed with polycystic ovarian syndrome. Journal of Obstetric, Gynecologic \& Neonatal Nursing 35, 385-392.

Van Manen, M. (1997). Researching lived experience: Human science for an action sensitive pedagogy (2nd ed.). Ontario, Canada: The Althouse Press.

Van Manen, M. (2014). Phenomenology of practice: Meaning-giving methods in phenomenological research and writing. Walnut Creek, CA: Left Coast Press, Inc.

Watson, J. (1995). Postmodernism and knowledge development in nursing. Nursing Science Quarterly, 8(2), 60-64.

Wilson, L.B., and Cleary, P.D. (1995). Linking clinical variables with health related quality of life. A conceptual model of patient outcomes. The Journal of the American Medical Association 273(1), 59-65.

Wong, S.Y.C. and Rivers, J.K. (2009). Does laser and or electro-optical synergy technology for removal of unwanted facial hair improves women's quality of life. Journal of the Dermatology Nurses' Association, 1(6), 338-342. 
World Health Organization. (1996). WHOQOL-BREF Introduction, Administration,

Scoring, and Generic Version of the Assessment. World Health Organization. Geneva, Switzerland.

Zanganesh, F.Z., Jafarabadi, M., Naghizadeh, M.M., Abdedinia, N., \& Haghollahi, F. (2012). Psychological distress in women with polycystic ovary syndrome from Imam Khomeini Hospital. Tehran. Journal of Reproduction and Infertility, 13(2), 111-115. Zigmond, A.S. and Snaith, R.P. (1983). The hospital anxiety and depression scale. Acta Psychiatrica Scandinavica 67, 361-370. 